\title{
Review Article \\ Roles of Vascular Endothelial Growth Factor in Amyotrophic Lateral Sclerosis
}

\author{
Ana Catarina Pronto-Laborinho, ${ }^{1,2}$ Susana Pinto, ${ }^{1,2}$ and Mamede de Carvalho ${ }^{1,2,3}$ \\ ${ }^{1}$ Institute of Physiology, Faculty of Medicine, University of Lisbon, Avenida Professor Egas Moniz, 1649-028 Lisbon, Portugal \\ ${ }^{2}$ Instituto de Medicina Molecular (IMM), Translational Clinical Physiology Unit, Avenida Professor Egas Moniz, \\ 1649-028 Lisbon, Portugal \\ ${ }^{3}$ Department of Neurosciences, Hospital Santa Maria, Centro Hospitalar Lisboa Norte, Avenida Professor Egas Moniz, \\ 1649-028 Lisbon, Portugal
}

Correspondence should be addressed to Mamede de Carvalho; mamedemg@mail.telepac.pt

Received 23 January 2014; Accepted 24 March 2014; Published 29 April 2014

Academic Editor: Deise M. F. Mendonça

Copyright (C) 2014 Ana Catarina Pronto-Laborinho et al. This is an open access article distributed under the Creative Commons Attribution License, which permits unrestricted use, distribution, and reproduction in any medium, provided the original work is properly cited.

\begin{abstract}
Amyotrophic lateral sclerosis (ALS) is a fatal devastating neurodegenerative disorder, involving progressive degeneration of motor neurons in spinal cord, brainstem, and motor cortex. Riluzole is the only drug approved in ALS but it only confers a modest improvement in survival. In spite of a high number of clinical trials no other drug has proved effectiveness. Recent studies support that vascular endothelial growth factor (VEGF), originally described as a key angiogenic factor, also plays a key role in the nervous system, including neurogenesis, neuronal survival, neuronal migration, and axon guidance. VEGF has been used in exploratory clinical studies with promising results in ALS and other neurological disorders. Although VEGF is a very promising compound, translating the basic science breakthroughs into clinical practice is the major challenge ahead. VEGF-B, presenting a single safety profile, protects motor neurons from degeneration in ALS animal models and, therefore, it will be particularly interesting to test its effects in ALS patients. In the present paper the authors make a brief description of the molecular properties of VEGF and its receptors and review its different features and therapeutic potential in the nervous system/neurodegenerative disease, particularly in ALS.
\end{abstract}

\section{Introduction}

Amyotrophic lateral sclerosis (ALS) is a devastating and fatal neurodegenerative disorder characterized by rapidly progressive degeneration of motor neurons in the spinal cord, brainstem, and motor cortex [1-4], leading to severe weakness and atrophy of voluntary muscles. However, it has heterogeneous clinical manifestations and variable progression rate [2-6]. ALS patients die mainly from respiratory failure, related to weakness of diaphragm and other respiratory muscles [7-9].

The median survival of ALS patients is 3-5 years after symptom onset $[5,10-12]$. The worldwide incidence and prevalence are 2-3/100 000 and 4-7/100 000, respectively [13], with a male/female ratio of $1.5: 1[5,10,11,14]$ approaching a 1:1 ratio in ALS patients with late symptom onset.
Most patients have first symptoms between 55 and 65 years $[5,14]$.

Most ALS cases are sporadic (SALS) (90-95\%) [6], but about $5-10 \%$ have a positive family history $[6,15]$. Autosomal dominant inheritance is the typical pattern in familial ALS (FALS); however penetrance is quite variable. Approximately $20 \%$ of FALS are caused by a missense mutation in the gene encoding $\mathrm{Cu} / \mathrm{Zn}$ super oxide dismutase (SOD1) [16]. More than 16 dysfunctional genes [17] have been described in FALS, including alsin (ALS2) [18, 19], senataxin (ALS4) [20], vesicle associated membrane protein B (VAPB, ALS8) [21], angiogenin $[22,23]$, TAR DNA binding protein (TARDBP or TDP-43) [24], RNA-binding protein fused in sarcoma (FUS) $[25,26]$, optineurin (OPTN) [27], valosin-containing protein (VCP) [28], and recently C9ORF72 [12, 29, 30]. Genetics in ALS is far 
from simple; some gene mutations are of questionable value in the etiopathogenesis of the disease, as VAPB [31], and in some subjects different gene mutations should act synergistically in order to cause disease expression-oligogeniticity [32].

The pathophysiological mechanisms of motor neurons degeneration in ALS are complex, multifactorial, and incompletely known. Some of these mechanisms include abnormal RNA metabolism and transcriptional abnormalities, oxidative stress, excitotoxicity (induced by glutamate), protein aggregates, mitochondrial dysfunction, neuroinflammation, cytoskeletal derangements, deregulated growth factors, impaired axonal transport and apoptosis $[6,33]$, abnormal calcium metabolism, and activation of proteases and nucleases [2]. Riluzole is the only drug currently approved in ALS, acting by decreasing glutamate activity in the central nervous system. However, its impact on survival is modest [34]. Interestingly, trials with other antiglutamatergic drugs have been negative in humans $[6,35]$.

In 2001, Oosthuyse and coworkers associated vascular endothelial growth factor (VEGF) with the pathogenesis of ALS [36]. VEGF is a proangiogenic factor that confers neuroprotection by promoting neuron survival in vivo and in vitro [37-39], in particular increasing life expectancy of the ALS mice model [40-43]. In addition, it exerts protective effects on other cells, such as lung epithelia, bone marrow, and bone cells. Oosthuyse and colleagues studied VEGF in mice with a deletion of the hypoxia-response element $\left(\mathrm{VEGF}^{\delta / \delta}\right)$. These mice developed adult-onset progressive motor neuron degeneration reminiscent of ALS [36] and showed reduced spinal cord and brain protein VEGF levels, suggesting that reduced hypoxia-mediated VEGF expression is associated with motor neuron degeneration.

In this review, we highlight the role of VEGF in ALS and its association with a potential therapeutic use.

\section{Biology of VEGF}

2.1. Members of the VEGF Family/Isoforms. VEGF is a homodimeric hypoxia-inducible glycoprotein, heparinbinding growth factor, which can induce angiogenesis in vivo [44], a potent mitogen, specific for vascular endothelial cells (ECs) $[45,46]$, but is also involved in some other processes such as inflammation and tumor progression [47]. In addition to hypoxia, other stimuli regulate the expression of VEGF gene, such as nitric oxide, estrogen, and a large variety of growth factors, like insulinlike growth factor (IGF-1), tumor necrosis factor alpha (TNF- $\alpha$ ), epidermal growth factor (EGF), transforming growth factor beta (TGF $\beta$ ), interleukin- (IL-) 6 , and IL1- $\beta$ [45].

Presently, the VEGF family (see Table 1) comprises seven elements: VEGF-A, VEGF-B, VEGF-C, VEGF-D, PLGF (placental growth factor), VEGF-E (Orf-VEGF), and Trimeresurus flavoviridis svVEGF (snake venom VEGF). The ability of various isoforms of VEGF to bind heparin in laboratory assays depends on the presence or absence of two different heparin-binding domains [48].
2.1.1. VEGF-A. VEGF-A is a dimeric glycoprotein with 33$42 \mathrm{kDa}$. Its gene expression is regulated by a variety of conditions such as hypoxia, growth factors, nitric oxide, p53 mutations, thyroid-stimulation hormone, and tumor promoters [49]. Higher levels of VEGF-A mRNA may be found in the adrenal gland, lung, kidney, and heart [50]. In humans, the gene encoding VEGF is located on the short arm of chromosome 6 (6p21.3) [51].

The VEGF-A gene has eight exons and seven introns $[52,53]$ and several homodimeric VEGF-A isoforms with biological activity have been identified: $\mathrm{VEGF}_{121}, \mathrm{VEGF}_{121 \mathrm{~b}}$, $\mathrm{VEGF}_{145}, \mathrm{VEGF}_{145 \mathrm{~b}}, \mathrm{VEFG}_{148}, \mathrm{VEGF}_{165}$ (predominant isoform), $\mathrm{VEGF}_{165 \mathrm{~b}}, \mathrm{VEGF}_{183}, \mathrm{VEGF}_{183 \mathrm{~b}}, \mathrm{VEGF}_{189}, \mathrm{VEGF}_{189 \mathrm{~b}}$, and $\mathrm{VEGF}_{206}$ [54-57], respectively, composed of 121, 145, 148, $165,183,189$, and 206 amino acid residues and resulting from alternative mRNA splicing [56-58].

2.1.2. Placental Growth Factor (PLGF). Placental growth factor (PLGF) is an angiogenic protein isolated from placenta, originally described in 1991 [59]. In humans, the PLGF gene is mapped on chromosome 14q24, and high levels of expression in placenta are found at all stages of gestation [49], as well as in the lungs, heart, skeletal muscle, and thyroid gland $[49,60,61]$.

Four PLGF isoforms are produced through alternative splicing, with different sizes and binding properties: PLGF1 (PLGF 131), PLGF-2 (PLGF 152), PLGF-3 (PLGF 203), and PLGF-4 (PLGF 224) [49, 62, 63]. PLGF-1 and PLGF-3 are nonheparin binding diffusible while PLGF-2 and PLGF-4 have heparin binding domains $[63,64]$. These molecules play an important role in the regulation of vascular differentiation [65].

2.1.3. VEGF-B. VEGF-B was discovered in 1996 [66]. Its gene is located on chromosome 11q13 [67] and comprises seven exons. Resulting from alternative splicing, two isoforms are expressed in human, VEGF-B ${ }_{167}$ and VEGF-B V $_{186}$ (of exon 6) [50], that bind to the tyrosine kinase VEGF receptor 1 (VEGFR-1). VEGF-B is a mitogenic factor for human ECs [68]. High levels can be observed in most tissues, in particular the neural tissues (retina, brain, and spinal cord) [69], myocardium, skeletal muscle, pancreas, prostate, and brown fat $[68,70-72]$.

Recently, VEGF-B has been extensively studied and considered as a strong cell survival factor for different types of cells, like neurons, vascular cells (pericytes, ECs and smooth muscle cells), and myocytes $[69,73,74]$.

2.1.4. VEGF-C and VEGF-D. Human VEGF-C gene is located on chromosome 4q34 [72] and the VEGF-D gene on chromosome Xp22.31 [75]. VEGF-C and VEGF-D isoforms result from proteolytic mechanisms, not from alternative splicing as VEGF-A and VEGF-B isoforms [70].

VEGF-C and VEGF-D have an important role in regulation of angiogenesis and lymphangiogenesis [72, 76-82] by promoting mitogenesis, migration, and survival of the ECs $[49,70,83,84]$. Initially, premature forms of VEGF-C and 


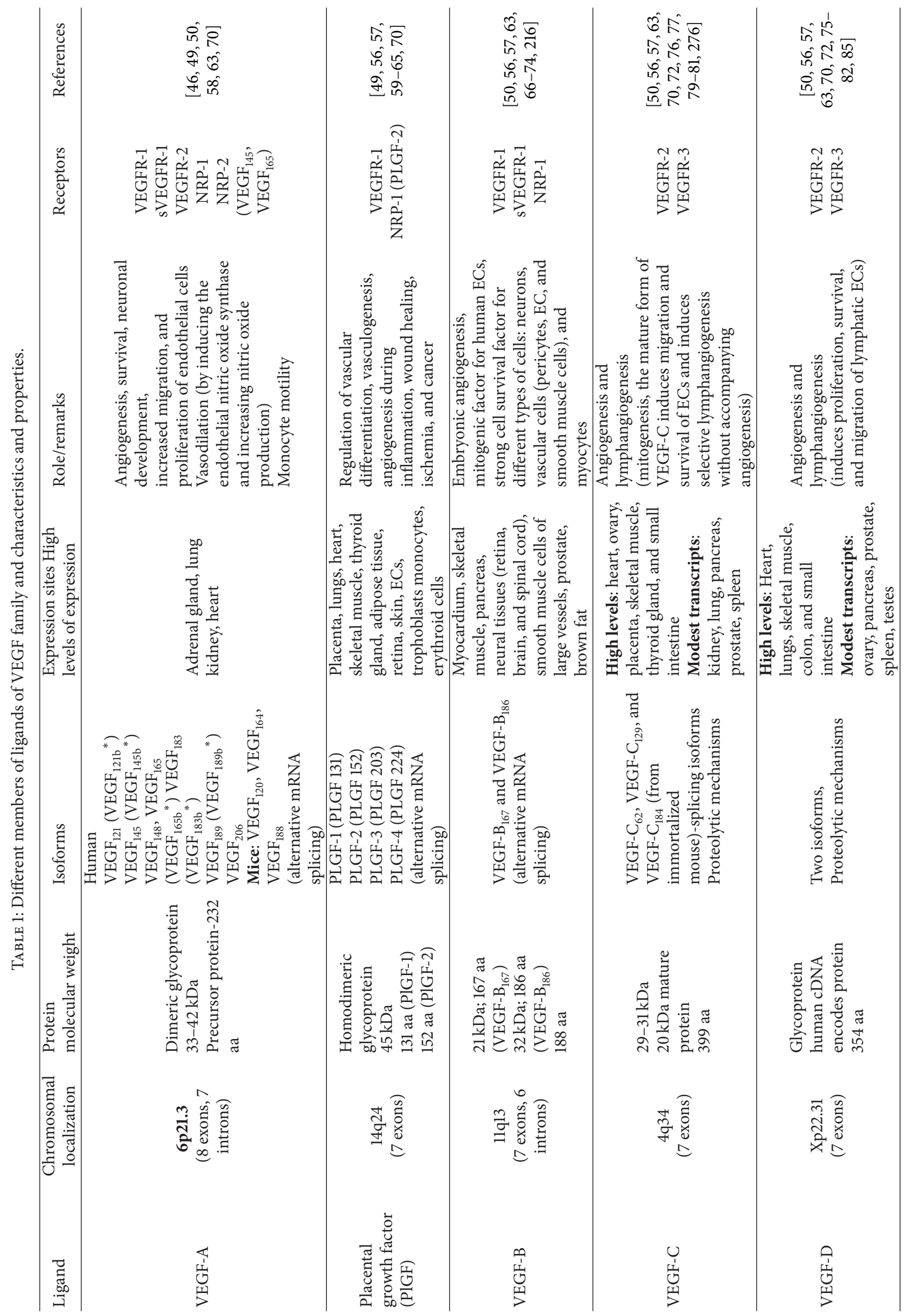




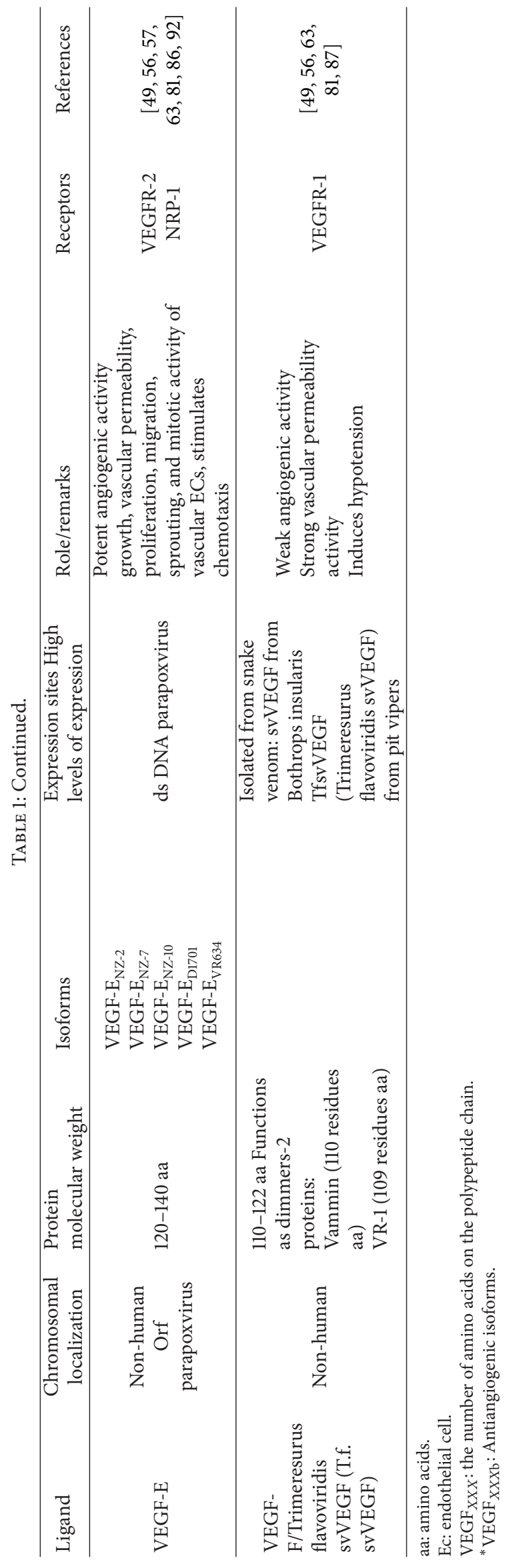


VEGF-D are synthesized and subsequently activated when binding to receptors $[70,81,85]$.

Human VEGF-C levels are higher in the placenta, ovaries, heart, small intestine, and thyroid gland while human VEGF$\mathrm{D}$ levels are higher in the heart, lungs, skeletal muscle, colon, and small intestine [50].

2.1.5. VEGF-E (Orf-VEGF). VEGF-E consists of 120-140 amino acids [81]. It has a potent angiogenic activity, similar to VEGF-A [86], more potent in stimulating the proliferation of ECs than $\mathrm{VEGF}_{165}$, although having no heparin-binding basic domain [49].

2.1.6. VEGF-F/Trimeresurus Flavoviridis svVEGF (T.f. $s v V E G F)$. In recent studies, the VEGF family of proteins was also found in snake venom, including the svVEGF from Bothrops insularis [49, 87] and TfsvVEGF (Trimeresurus flavoviridis svVEGF) from pit vipers. Comprising 110122 amino acid residues, svVEGF functions as dimmers [49]. TfsvVEGF strongly binds to VEGFR-1 but weakly to VEGFR-2, resulting in a weak angiogenic activity and a strong vascular permeability activity [81].

2.2. VEGF Receptors. VEGF binding sites have been identified on the surface of vascular ECs both in vivo and in vitro $[52,88]$. Two distinct classes of VEGF receptors (VEGFR) exist-tyrosine kinases and nontyrosine kinase receptors [52, 55].

2.2.1. VEGF Receptors Tyrosine Kinases. VEGFR family has three members (see Table 2): VEGFR-1 (fms-like tyrosine kinase-1 or Flt1), VEGFR-2 (KDR in humans, Flk1 in mice), and VEGFR-3 (fms-like-tyrosine kinase-4 or Flt-4). Both VEGFR-1 and VEGFR-2 contain seven immunoglobulin-like domains in the extracellular domain (VEGFR-3 contains only six), a single transmembrane region, and a consensus tyrosine kinase sequence interrupted by a kinase insert domain [50, $52,89,90]$.

VEGFR-1 and VEGFR-2 feature a central role in regulating angiogenesis, while VEGFR-3 stimulates lymphangiogenesis [52, 81, 91].

VEGFR-1. Human VEGFR-1 consists of 1338 amino acids [92] and is located on chromosome 13q12 [93]. VEGFR1 binds not only to VEGF-A and VEGF-B but also to PLGF with high affinity. It is expressed in ECs, pericytes, placental trophoblasts, osteoblasts, renal mesangial cells, monocytes/macrophages, and some hematopoietic stem cells $[52,94]$. It has a weak mitogenic action in ECs [70]. VEGFR-1 expression is upregulated during hypoxia by a hypoxia-inducible factor-1- (HIF-1-) dependent mechanism [95]. Interestingly, the soluble form of VEGFR-1 (soluble Flt1) after undergoing alternative splicing inhibits VEGF activity $[52,96]$.

VEGFR-1 knockout mice die at embryonic day 8.5 to 9.0 stage (E8.5 to 9.0) from blood vessels disorganization and excessive growth, not from poor vascularization [70, 92]. This strongly suggests that VEGFR-1 offsets signals that induce angiogenesis by suppressing proangiogenic signals in the embryo (achieving a balance in physiological angiogenesis) [92].

In humans, abnormal high levels of soluble protein and sVEGFR-1 were found in serum in women with preeclampsia, accompanied by decreases in the circulating free PLGF and VEGF levels, possibly leading to EC dysfunction in the maternal and placental vessels $[97,98]$.

VEGFR-2. VEGFR-2 is located on chromosome $4 \mathrm{q} 11 \rightarrow \mathrm{q} 12$ [99]. It binds to VEGF-A, VEGF-C, and VEGF-D and has strong tyrosine kinase activity, appearing to be the most important VEGF receptor, inducing mitogenesis, migration, and permeability of the ECs $[50,100,101]$. VEGF has higher binding affinity for VEGFR-2 than for VEGFR-1. Selective activation of VEGFR-1 and VEGFR-2 shows that the latter is the primary signal transmission of VEGF in ECs $[52,70]$.

VEGFR-2 activation induces production of platelet activating factor (PAF) by ECs, stimulating their mitosis and migration and increasing vascular permeability $[50,85]$. It is also expressed in osteoblasts, cells of the pancreatic duct, neuronal cells, retinal progenitor cells, hematopoietic stem cells, and megakaryocytes. In nervous system, VEGFR-2 stimulates migration, proliferation, and survival of different neural cell types $[90,102,103]$.

Inactivation of the VEGFR-2 gene in mouse resulted in the death of the embryo after E8.5 and E9.5, due to nondevelopment of embryonic vasculature, blood islands, and hematopoietic cells [104]. Therefore, VEGFR-2 signaling is essential for the development of the mouse embryo vessels $[70,92,104-106]$.

VEGFR-3. VEGFR-3 binds to VEGF-C and VEGF-D [52, 81, $85,91,107]$. Two human isoforms are described, resulting from alternative splicing and differing in their C-terminal [108].

Expression of VEGFR-3 begins at E8.5 in all embryonic mouse ECs. Afterwards, its expression is observed in developing venous and lymphatic vessels $[70,109,110]$. VEGFR-3 and their ligands play an important role in lymphangiogenesis $[55,111]$. It is involved in mitogenesis, differentiation, and survival of lymphatic EC $[107,110,112]$. It is also expressed in osteoblasts, neuronal progenitor cells [113], and macrophages [111].

Hamada and coworkers showed that mice embryos with VEGFR-3 deficiency had abnormal vasculature and developed severe anemia and concluded that VEGFR-3 activity is critical in hematopoiesis and vasculoangiogenesis [114]. In another study, [115] it was observed that large vessel remodeling and maturation were abnormal in VEGFR-3 null mice embryos, causing abnormal fluid in the pericardial cavity and resulting in death after E9.5 by cardiovascular failure. The authors concluded that VEGFR-3 plays an essential role in the development of the cardiovascular system in an embryo before the emergence of lymphatic vessels $[109,111,115]$. 


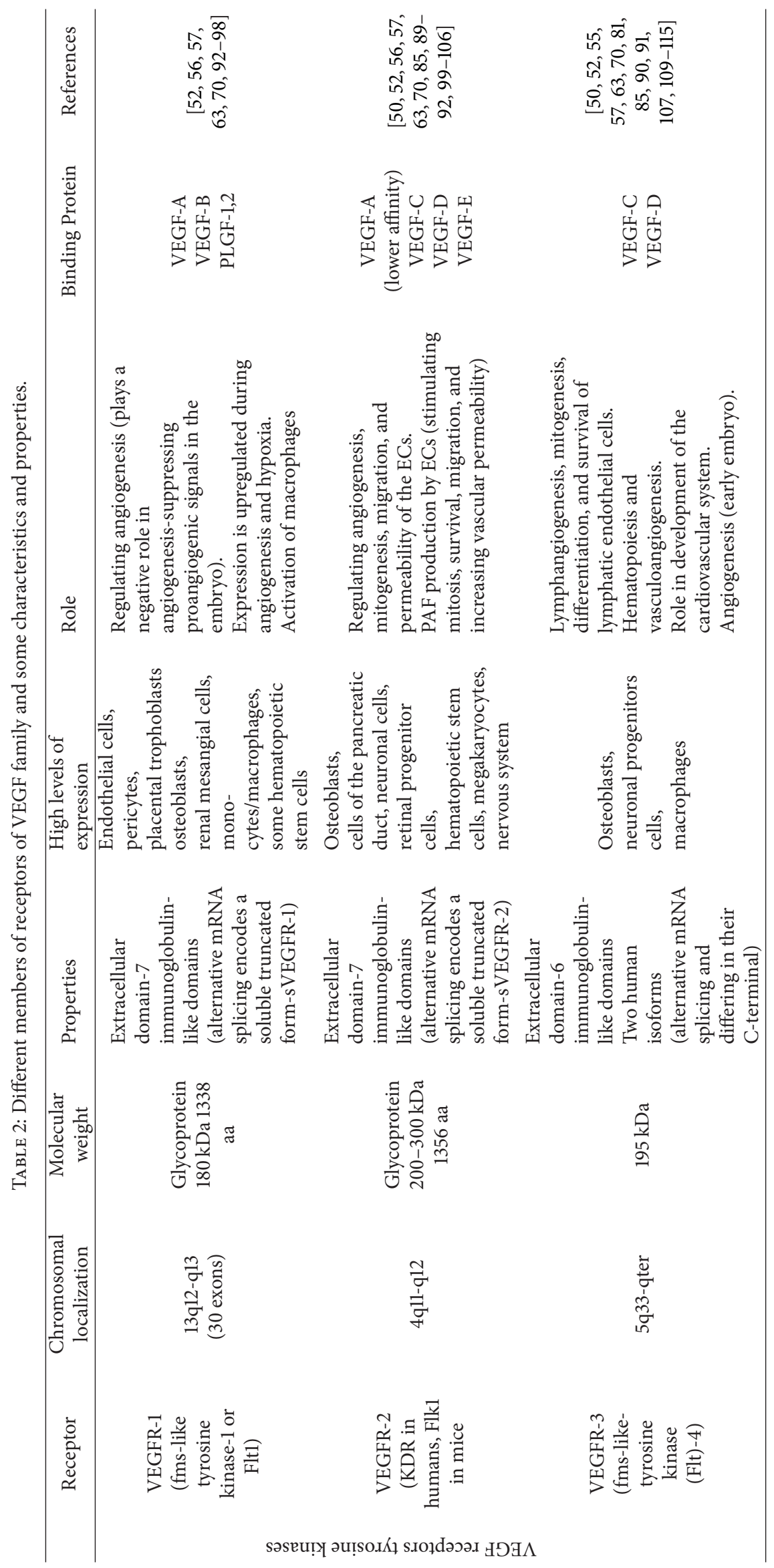




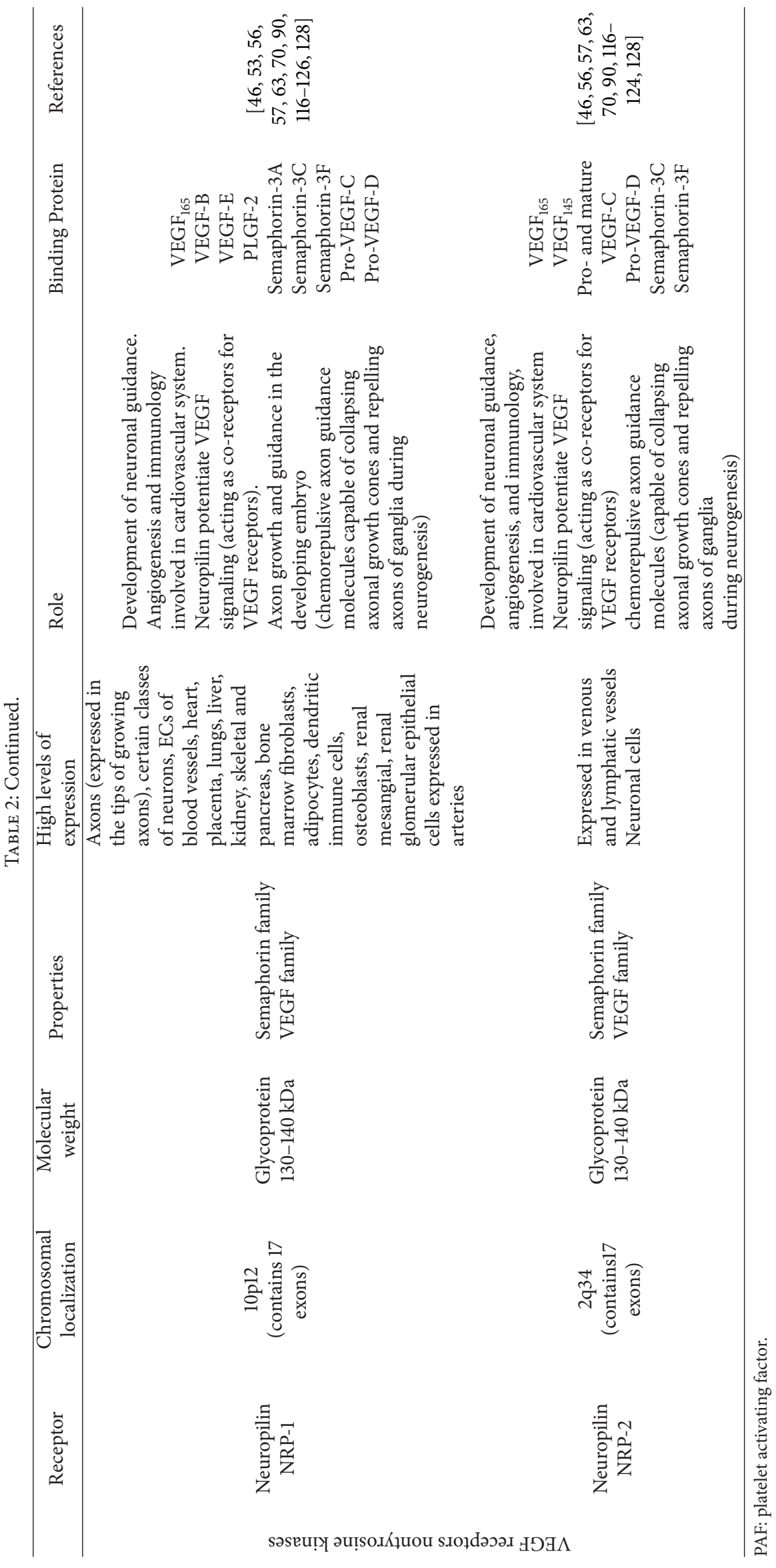




\subsubsection{VEGF Receptors Nontyrosine Kinases}

Neuropilins: NRP-1 and NRP-2. Neuropilin-1 (NRP-1) and neuropilin-2 (NRP-2) are nontyrosine kinase receptors. Neuropilins are single-spanning transmembrane glycoproteins of about $130-140 \mathrm{kDa}$, and have $45-50 \%$ sequence identity. NRP-1 and NRP-2 genes are located on chromosomes 10p12 and 2q34, respectively [116]. NRP-1 and NRP-2 bind to VEGF and PIGF. NRP-1 also binds to VEGF-B, whilst NRP-2 binds to VEGF-C [70, 116]. Both receptors bind to heparin-binding splice forms of VEGF: VEGF $_{165}$ binds to NRP-1 and NRP-2; VEGF 145 binds to NRP-2 [117-119]. Neuropilins potentiate VEGF signaling by acting as coreceptors for VEGF receptors [90, 120, 121].

These receptors play a fundamental role in the development of neuronal guidance, angiogenesis, and immunology and are also involved in cardiovascular system [116-118, $121,122]$. They belong to the class-3 semaphorin subfamily $[117,118,122,123]$, family of secreted molecules mediating repulsive signals in neuronal axon process guidance [116]. In a chimeric mice study, overexpression of NRP- 1 caused excessive blood vessel formation and heart malformation $[116,124]$.

In a recent study, knockout NRP-1 mutant mice died at embryo stage E13 from impaired neural vascularization, transposition of large vessels, and weak vascular network development in the yolk sac. Therefore, the authors concluded that NRP-1 is both effective in embryonic vessels formation and in nerve fiber guidance [125]. A study in zebrafish model underscored that NRP-1 is required for the VEGF-dependent angiogenesis $[46,126]$. A study with NRP2 knockout mice demonstrated severe abnormalities in the development of capillaries and small lymphatics [127]. In NRP-1 and NRP-2 double knockout mice, the embryonic mice died at E8.5 with avascular yolk sacs [128].

2.3. Regulation of VEGF Expression. VEGF expression is stimulated by several factors, such as oncogenes, thyroidstimulating hormone, estrogen, nitric oxide (NO), hypoxia, and growth factors. VEGF gene contains various potential binding sites for transcriptional regulators, like activator protein-1 (AP-1), activator protein-2 (AP-2), HIF-1, specific protein (SP-1), Egr-1, signal transducer, and activator of transcription-3 (Stat-3) [55, 129].

We will shortly mention the key factors and conditions related to regulation of VEGF expression.

2.3.1. Oxygen Tension. Erythropoietin (EPO) is a glycoprotein hormone/growth factor. Its gene is localized on chromosome 7 (7pter-q22) [130]. EPO-producing cells, localized in the liver and kidneys, have the ability to sense oxygen concentration and respond to systemic hypoxia by increasing EPO gene transcription $[95,131,132]$. EPO controls erythropoiesis and, thereby, oxygen transportation by circulating erythrocytes.

Reduced local oxygen tension induces angiogenesis [133], by regulating the expression of a variety of genes. In particular, VEGF mRNA expression is stimulated [46, 134]. Moreover, VEGF production is upregulated by hipoglicemia and acidosis $[129,131,135]$. Hypoxic transcriptional regulation of VEGF-A is mediated by HIF-1, a heterodimeric protein transcription factor [136]. Indeed, HIF-1 is also activated by other environmental stresses as low $\mathrm{pH}$, cytokines, and several growth factors [137].

HIF-1 has two subunits, HIF-1 alfa (120-kDa) and HIF-1 beta (91-94-kDa), both being basic-helix-loop-helix Per-aryl hydrocarbon receptor nuclear translocator-Sim (PAS) family of transcription factors [138-141]. Under normoxic conditions, HIF-1 alfa (HIF-1 $\alpha$ ) is degraded by ubiquitin pathway (proteasome degradation-26S proteosome) $[142,143]$. HIF$1 \alpha$, hydroxylated by prolyl hydroxylases proteins (PHDs), interacts with the von Hippel-Lindau (pVHL) protein, a component of the E3 ubiquitin ligase complex, marking HIF-1 $\alpha$ for degradation [144-146]. However, under hypoxic conditions, PHDs are inactive, HIF-1 $\alpha$ increases dramatically, and the fraction that is ubiquitinated decreases [143, 147]. HIF- $1 \alpha$ translocates into the nucleus and associates with HIF beta (HIF- $\beta$ ) and the coactivators $\mathrm{p} 300 / \mathrm{CBP}$ to induce gene expression by binding to the conserved [A/G] CGTG hypoxia-responsive element (HRE) [148]. Hypoxia promotes the induction of transcription and the stabilization of VEGF mRNA through proteins that bind to sequences located in the region UTR ( $3^{\prime}$ unstranslated region) of the VEGF mRNA [149].

2.3.2. Cytokines and Growth Factors. VEGF expression in different cells is upregulated by cytokines (IL-1 $\alpha$, IL-1 $\beta$, IL6 , and TNF- $\alpha$ ), prostaglandins (E1 and E2), and numerous growth factors (transforming growth factor $\alpha$, transforming growth factor $\beta$, epidermal growth factor, fibroblast growth factor 4 , keratinocytes growth factor, insulin-like growth factor-1, platelet-derived growth factor $\mathrm{BB}$, and basic fibroblast growth factor) [46, 136, 150-159]. The upregulated VEGF mRNA expression suggests that paracrine or autocrine release of such factors acts synergistically with local hypoxia to increase VEGF release [46, 52, 65, 149], with influence on angiogenesis/permeability in inflammatory disorders $[46,52,149,150]$.

2.3.3. Tumor Suppressor Genes and Oncogenes. The involvement of altered oncogenes and suppressor genes is crucial. The uncontrolled typical tumoral growth results from activation of oncogenes and loss of genes/tumor suppressor proteins at different sites in cell signaling pathways [160]. Oncogenic mutations or amplification of Ras results in VEGF upregulation. Some studies indicate that Ras-dependent VEGF expression is necessary, although insufficient, for progressive tumor growth in vivo $[52,161]$.

The overexpression of the VEGF gene can occur due to a mechanism of inactivation of the tumor suppressor gene. The von Hippel Lindau (VHL) tumor suppressor gene was implicated in the regulation of VEGF gene expression [162]. VHL protein provides a negative regulation of a group of hypoxia-inducible genes, such as VEGF, platelet-derived growth factor B chain, and the glucose transporters GLUT-1 genes [163]. In presence of a mutant VHL, mRNAs for such 
genes were produced both under normoxic and hypoxic conditions [65].

\section{VEGF in the Nervous System}

VEGF has an important role in vascular growth regulation and development. Moreover, VEGF produces direct effects in a variety of neuronal cells, including neuritic outgrowth, axon guidance, neuronal survival, and neuronal migration. Recent studies have shown that in adverse conditions for neuronal cells, such as oxidative stress, hypoxia, or glucose deprivation, VEGF acts as a mediator of multiple mechanisms inhibiting cell death and stimulating neurogenesis [36-38, 90, 103, 164168].

3.1. VEGF in Neurogenesis. Production of progenitor cells and neurons occurs during development and in adult age. The two fundamental regions contributing to neurogenesis in the adult mammalian brain are the subventricular zone (SVZ) of the lateral ventricles and the subgranular zone (SGZ) in dentate gyrus of the hippocampus [169]. In both regions, neurogenesis occurs in the vicinity of blood vessels by the proliferation of neural stem cells (NSCs) in small clusters $[90,167,170]$.

In adult brain, neurogenesis is a dynamic process regulated by several stimuli, in particular growth factors (epidermal growth factor, EPO, brain-derived neurotrophic factor, stem cell factor, and VEGF), glucocorticoids, sex hormones, and excitatory neurotransmitters [164]. It can also occur in response to critical situations such as cerebral ischemia, mechanical trauma, and seizures [164, 166, 168, 169, 171]. In addition, these injuries drive migration of new neurons into affected regions to promote tissue repair [171].

VEGF has an important role in adult neurogenesis [90, 172], participating in the crosstalk between ECs and NSCs within vascular niches. This process can be highlighted by the presence of cells labeled with bromodeoxyuridine (BrdU) and doublecortin (Dcx), which are markers of proliferation and neuronal lineage, respectively [171]. In animal studies, intracerebroventricular administration of VEGF stimulates neurogenesis. Additionally, other studies have stressed that VEGF favors survival of newly formed neurons $[103,164$, 166]. The role of VEGF in neurogenesis is rather complex. Testosterone-induced neurogenesis is preceded by an upregulation of VEGF and VEGFR-2. Brain-derived neurotrophic factor (BDNF), secreted by ECs, acts through VEGF increase subsequently stimulating neural cell proliferation [173]. Granulocyte colony-stimulation factor (G-CSF) stimulates neurogenesis by increasing the release of VEGF from NSCs and the expression of VEGFR-2 in those cells. VEGFR-2 tyrosine kinase inhibitor blocks the neurogenesis stimulated by G-CSF $[172,174]$.

Antidepressant drugs stimulate neuron proliferation in part due to the upregulation of VEGF and VEGFR-2 signaling in the hippocampus [175]. This positive effect is lost by previous intraventricular infusion of a VEGFR-2 inhibitor. In behavioral models, VEGF infusion into the brain mimics the positive effect of antidepressants drugs on neurogenesis
[167, 175-177]. Hippocampus VEGF expression is increased in animals exposed to enriched environment conditions and on learning protocols. The hippocampal overexpression of VEGF via viral gene transfer led to increased neurogenesis and improved cognition. In a study, the use of a dominantnegative mutant KDR/VEGFR-2 (mKDR) resulted in negative effects on neurogenesis and learning process, but not inhibiting the proliferation of ECs $[172,178]$.

VEGF-B participates in the regulation of neurogenesis in adult brain. Intracerebroventricular VEGF-B administration leads to BrdU incorporation in neuronal lineage cells in vivo and in vitro. Moreover, VEGF-B knockout mice showed reduced neurogenesis, coherent with its neurogenesis-promoting activity $[165,179]$. VEGF-C promotes neurogenesis of neural progenitor cells expressing the VEGFR-3 [113]. Overexpression of VEGF-C stimulates VEGFR-3 expressing NSCs as well as neurogenesis in the SVZ, but not affecting angiogenesis. Reciprocally, SVZ neurogenesis is diminished by conditional deletion of VEGFR-3 in neural cells and by blockage of VEGFR-3 signaling with antibodies [180].

3.2. VEGF in Neuroprotection and Neuroregeneration. Experimental studies in vivo and in vitro demonstrated the neuroprotective, neurotrophic, and angiogenic properties of VEGF [36, 37] through its action on various neuronal cell types $[42,43,90,166]$. The effects are observed in hippocampus, as well as in dopaminergic, cerebellar, and retinal neurons, and also in the peripheral nervous system. VEGF protects these cells against death induced by a wide variety of different stress conditions like hypoxia and excitotoxicity stimuli $[37,42,90,171,181,182]$. In hippocampus, protection against excitoxicity occurs via two pathways: phosphatidylinositol 3-kinase (PI3K)/Akt (PI3K$\mathrm{K} / \mathrm{AKT}$ ) and mitogen-activated protein kinase/extracellular signal-regulated kinase (MEK)-extracellular signal regulated kinase (ERK) (MEK/ERK) [183]. VEGFR-2 is predominantly responsible for mediating this neuroprotective effect, although VEGFR-1 can also have some of these effects [90].

Some studies demonstrated that VEGF exerts its neuroprotective action directly by inhibiting programmed cell death (apoptosis). VEGF also exerts neuroprotective effects indirectly through its action on multiple processes such as angiogenesis, increased blood brain barrier permeability to glucose and activation of antioxidants $[90,181,184]$.

3.2.1. Direct Neuroprotective Functions of VEGF. Several studies support the role of VEGF in increasing neuron survival when subjected to hypoxia, by inhibition of Caspase 3 activation via Caspase 9, thereby reducing apoptosis [103, $164,166,184-186]$. The increased expression of VEGFR-2 in neurons, when subjected to hypoxia and glucose deprivation, indicates that this receptor is especially involved in the neuroprotective effect of VEGF $[184,186,187]$.

3.2.2. Indirect Neuroprotective Functions of VEGF. VEGF also has an indirect neuroprotective function that affects neuronal survival in critical conditions. It promotes heme oxygenases 
TABLE 3: VEGF neurotrophic activity (adapted from Keifer et al., $2014[198])$.

\begin{tabular}{llc}
\hline VEGF factor & Role & References \\
\hline & Neurogenesis & {$[103,277,278]$} \\
& Nerve migration & {$[279]$} \\
& Axonal guidance & {$[167,280,281]$} \\
& Survival/neuroprotection & {$[39,41,282]$} \\
& Protective effects in adverse & \\
VEGF-A & Conditions: & {$[36,37,182,183$,} \\
& Hypoxia & $212,251,283$, \\
& Serum deprivation & $284]$ \\
& Excitotoxicity & \\
& Mechanical trauma & {$[165,217]$} \\
\hline \multirow{2}{*}{ VEGF-B } & Shemical toxicity & \\
& neurval: retinal and cortical & {$[113,285,286]$} \\
VEGF-C & Nervous system development & Proliferation and activation of \\
& astroglia and microglia & {$[279,287]$} \\
\hline \multirow{3}{*}{ VEGF-D } & Survival/neuroprotection & \\
& $\begin{array}{l}\text { Development of embryonic } \\
\text { stem cells }\end{array}$ & \\
\hline PLGF & Survival/neuroprotection & {$[288,289]$} \\
\hline
\end{tabular}

TABLE 4: VEGF activity in dendritogenesis, synaptic plasticity, and axonal growth in adult brain (adapted from Mackenzie and Ruhrberg, 2012 [167]).

\begin{tabular}{lcc}
\hline VEGF & Role & References \\
\hline \multirow{3}{*}{ VEGF } & Dendritogenesis & {$[167,172,282,290-292]$} \\
& Synaptic plasticity & {$[90,172,290-295]$} \\
& Axonal growth & {$[102,167,172,280-$} \\
& & $282,296-298]$ \\
\hline
\end{tabular}

antioxidative activity [188-190], increases brain glucose supply by GLUT-1 transport pathway, dilates cerebral arterioles, and induces endothelial fenestrations [191]. Moreover, angiogenesis exerts neuroprotective effects by increasing cerebral blood flow [37, 184].

VEGF has neuroregenerative properties. Bearden and colleagues used a model of axotomy to show regeneration mediated by VEGFR-2 activation. In addition, VEGF sequestration by sVEGFR-1 impairs the regeneration of axotomized nerves $[192,193]$. VEGF promotes increased growth cone area of sympathetic neurons via VEGFR-2 and NRP-1 mediation [193]. Other studies support VEGFR-1 signaling induction of chemotaxis and microglial proliferation [194]. VEGF also acts on glial cells in the adult nervous system, promoting neuron survival $[39,195,196]$.

The various roles of VEGF proteins in the nervous system of the adult brain are briefly summarized in Tables 3 and 4 .

\section{Role of VEGF in ALS}

\subsection{Animal Models}

4.1.1. Rats and Rodents Models. Strong evidence of the role of VEGF in the nervous system comes from studies in ALS.
In the past decade, VEGF has been implicated in motor neuron degeneration in mice. In 2001, Oosthuyse and colleagues found that transgenic mice with homozygous deletion of the hypoxia-response element in the VEGF promoter (VEGF $\delta / \delta$ mice) gene showed reduced VEGF levels by about $25-$ $40 \%$ in the neural tissue. The affected mice developed limb weakness and neurogenic muscular atrophy by five weeks of age, with electromyographic signs of muscle denervation and reinnervation associated with loss of motor neurons in the spinal cord. Approximately $60 \%$ of the mice died before or at birth due to severe lung vascular alterations $[36,42$, 181, 197, 198]. A follow-up study [40] used mice that resulted from crossing SOD1 ${ }^{\mathrm{G} 93 \mathrm{~A}}$ and $\mathrm{VEGF}^{\delta / \delta}$ models [199]. This mice model showed an earlier onset of muscle weakness and shorter survival [40]. Wang et al. crossed SOD ${ }^{\mathrm{G} 93 \mathrm{~A}}$ mice with mice overexpressing VEGF-A in neurons. These double transgenic mice had a significant delay in motor neuron loss and in the onset of weakness, resulting in an increased survival compared to the single transgenic mice [3].

Interestingly, decreased VEGF expression in the spinal cord of SOD $1^{\mathrm{G} 93 \mathrm{~A}}$ mice has been reported. In vitro models suggest that it derives from reduced stability of mRNA VEGF. Indeed, Lu and colleagues identified that mutant SOD1 leads to downregulation and destabilization of mRNA VEGF [200]. It was shown that in mutant SOD1 mice but not in wild-type mice, ribonucleoprotein complex with adenine and uridine-rich stability elements (ARE) is present in the $3^{\prime}$ unstranlated region (UTR) of mRNA VEGF, resulting in lower VEGF expression levels [200-202]. Contrary to the above reports, Van Den Bosch et al. described no significant difference in the levels of VEGF-A in the spinal cord of SOD $1{ }^{\mathrm{G} 93 \mathrm{~A}}$ mice when compared to wild-type controls [203] and Murakami et al. reported a higher VEGF expression level in the spinal cord of SOD $1^{\mathrm{G} 93 \mathrm{~A}}$ mouse [204]. It seems that VEGF expression in SOD $1^{\mathrm{G} 93 \mathrm{~A}}$ motor neurons is minimally upregulated by hypoxia $[90,204]$, which reinforces the role of VEGF expression in the pathogenesis of motor neuron degeneration [204]. Exposition of mutant SOD $1{ }^{\mathrm{G} 93 \mathrm{~A}}$ mice to prolonged periods of hypoxia did not affect their life span after the upregulation of VEGF in the spinal cord [203].

Resulting from the VEGF role in perfusion of the brain and spinal cord $[36,172,203,205]$ a reduction of neuronal perfusion in the symptomatic $\mathrm{VEGF}^{\delta / \delta}$ mice was described [36]. Moreover, decreased spinal cord blood flow has been observed in the presymptomatic mutant SOD1 mice [8, $36,206]$. However, it still remains unclear whether the reduced neural perfusion is present before the onset of motor neuron degeneration or is just a consequence of neuronal loss.

As most trophic effects on motor neurons are mediated by VEGFR-2 and NRP-1 [42, 207, 208], several authors suggest that coexpression of VEGF and VEGFR-2 may lead to supplementary positive effects on these cells [36, 209, 210]. When the transgenic Thy:VEGFR-2 mice, which leads to an overexpressing VERGFR-2 under control of Thy1.2 promoter that triggers its expression in postnatal neurons, were intercrossed with $\mathrm{SOD}{ }^{\mathrm{G} 93 \mathrm{~A}}$, the resulting double transgenic mice, Thy-VEGFR-2 X SOD1 ${ }^{\mathrm{G} 93 \mathrm{~A}}$, demonstrated that 
VEGFR-2 overexpression in motor neurons retards degeneration of spinal motor neurons in SOD $1^{\mathrm{G} 93 \mathrm{~A}}$ mice $[90,211]$. A recent study showed that the administration of recombinant VEGF $_{165 b}$ exerts neuroprotection against multiple insults. The neuroprotection is dependent on the activation of the VEGFR-2 and MEK1/2, and the inhibition of caspase 3 induction [212].

4.1.2. Zebrafish Models. In zebrafish embryos, the overexpression of mutant SOD1 (mSOD1) protein revealed the induction of a dose-dependent motor axonopathy. Lowering VEGF induced a more severe phenotype, whereas upregulating VEGF rescued mSOD1 axonopathy [213].

More recently, Da Costa created a new model of zebrafish, the T70I mutant (mutant zebrafish line). This mSOD1 protein zebrafish replicates several of the features of human ALS, such as early neuromuscular junction abnormalities, adultonset motor neuron disease phenotype, and susceptibility to oxidative stress. This model can be a useful in vivo tool for therapeutic screening [214].

4.1.3. Culture Models. It was observed in a study using motor neuron models, in cultures containing mutant SOD ${ }^{\mathrm{G} 93 \mathrm{~A}}$, through administration of adenovirus vector, that VEGF increased neurons survival [215]. Tovar-y-Romo and Tapia showed the importance of the PI3K/AKT survival pathway role, as well as the inhibition of p38 MAPK (p38 mitogen activated protein kinase)-stress-activated protein kinase, in the protective mechanism exerted by VEGF against excitotoxic spinal motor neuron death in vivo, thus suggesting that VEGFR-2, the $\mathrm{p} 38 \mathrm{MAPK}$, and PI3K pathway constitute appealing therapeutic targets for ALS [208].

Increase in motor neuron survival by VEGF has been reported even in adverse conditions such as hypoxia, hypoglycemia, and deprivation of serum. However, it seems that VEGF does not protect neurons from excitotoxicity [203].

4.2. VEGF-B in ALS. VEGF-B, recently identified by Grimmond et al. (1996) [66] and Olofsson et al. (1999) [72], appears to provide a potent survival and protective factor for neurons, namely, cortical, retinal, and spinal cord motor neurons $[165,216,217]$. Moreover it is a survival factor for endothelial cells, pericytes, and smooth muscle cells [201, 218, 219]. Administration of small quantities of VEGF-B causes neuroprotection without causing adverse effects or vascular blood-brain barrier leakiness [220]. In contrast, VEGF-A administration is related to angiogenesis and edema [220, 221]. In VEGF-B in knockout mice, Sun and colleagues described a $40 \%$ increase of lesion size after cerebral ischemia. It was also found that VEGF-B protected cultured cortical neurons from hypoxic brain injury [165]. More recently Li and coworkers [201, 217, 219] showed that VEGF-B acts as a potent survival factor by suppressing the expression of BH3-only protein and other apoptotic cell death-related genes [201, 217, 219].
When crossing SOD1 $1^{\mathrm{G} 93 \mathrm{~A}}$ with $\mathrm{VEGFB}^{-/-}$mice two lines SOD $1^{\text {G93A }}$ VEGF- $^{+/-}$and VEGF-B SOD $1^{\text {G93A }}$ VEGF$\mathrm{B}^{-/-}$are obtained. Double transgenic mice SOD $1{ }^{\mathrm{G} 93 \mathrm{~A}}$ VEGF$\mathrm{B}^{-/-}$developed the most severe form of motor neuron disease [211, 220, 222]. Further treatment with VEGF-B has changed clinical phenotype to a milder form, as observed for VEGF-A [211]. Since VEGF-B shows weaker angiogenic and permeability properties than VEGF-A, it has an excellent safety profile.

\subsection{VEGF in Human ALS}

4.3.1. Genetic Studies. Several clinical studies point to the involvement of VEGF in ALS. However, clinical reports failed to identify any specific VEGF mutation [40, 223-225]. A study based on Swedish, English, Belgian, Russian, and American patients displayed an association between 2 haplotypes determined by 3 single-nucleotide polymorphisms (SNPS) $-2.578 \mathrm{C} / \mathrm{A},-1.154 \mathrm{~L} / \mathrm{C}$, and $-634 \mathrm{G} / \mathrm{C}-$ in the VEGF upstream promoter/leader sequence of the VEGF gene with an increased risk of ALS [40, 226-228]. Other studies reported no association between these polymorphisms and SALS in various populations, as in Chinese [229], Italian [230], Dutch [231], German [232], British [224], and North American [233]. A meta-analysis was performed in order to clarify those different results: three polymorphisms were studied, involving 7000 patients from various countries in Europe and America. This study did not confirm the original conclusion that VEGF haplotypes increase the risk of ALS in humans but confirmed a significant association of the VEGF2578 AA genotype and ALS susceptibility in males [226].

4.3.2. Plasma, Serum, and Cerebral Spinal Fluid (CSF). There are conflicting reports of VEGF levels in CSF, serum, and plasma in humans with ALS. Normally, VEGF levels are much higher in serum than in plasma and even lower in CSF. Measurements in serum are potentially contaminated by release of VEGF from platelets [234]. Serum levels of VEGF in ALS have been reported as unaltered [235] or higher than normal [236, 237]. Lambrechts et al. [226] found that plasma VEGF levels were around 50\% lower in ALS patients than in controls, in particular in those carrying at-risk VEGF genotypes. However, in other studies plasma levels of VEGF were within normal limits in ALS patients [237-240] without significant change in patients with hypoxemia $[237,239,240]$. Indeed, Moreau and coworkers showed that HIF-1 was not activated by hypoxia in monocytes from ALS patients [241].

Devos et al. [238] studied CSF VEGF levels in 24 patients with ALS. They reported lower CSF levels in the early phase of the disease when compared with other disease controls, but similar to levels recorded in healthy subjects. In contrast, Gupta et al. [242] found that VEGF levels were increased in CSF and serum in ALS in general and further increased with hypoxia. In long duration ALS, Ilzecka [243] found that the VEGF level in CSF was increased. The VEGF level in CSF is not clearly associated with hypoxia in ALS, as a lack of upregulation of CSF VEGF during hypoxemia has been reported, when compared with hypoxemic controls [244]. 
TABLE 5: Summary of themode of administration and delivery form of VEGF, its advantages, and disadvantages (adapted from Keifer et al., 2014 [198]).

\begin{tabular}{ll}
\hline Direct & $\begin{array}{c}\text { Administration } \\
\text { Indirect/Remote }\end{array}$ \\
& $\begin{array}{l}\text { (i) The product is delivered } \\
\text { in the CNS secondarily } \\
\text { (ii) Necessary higher dosages } \\
\text { (i) Direct access to the target } \\
\text { area }\end{array}$ \\
$\begin{array}{ll}\text { (ii) Decreases complications } \\
\text { in areas outside the } \\
\text { therapeutic scope }\end{array}$ & $\begin{array}{l}\text { administration } \\
\text { (iii) Product should have the } \\
\text { (ii) Smaller dose required } \\
\text { ability to cross the BBB, pial } \\
\text { barrier, and be transported } \\
\text { retrogradely by CNS }\end{array}$ \\
\hline Delivery &
\end{tabular}

Cells that produce or secrete VEGF-A

Use of a viral vector or nonviral to produce VEGF-A or a protein

that enhances expression of endogenous VEGF-A (transcription factor)

Immediate delivery of VEGF-A protein to the target region

Carilho et al. found no correlation between VEGF plasma levels and forced vital capacity, $\mathrm{PaO}_{2}$ or $\mathrm{PaCO}_{2}$, meaning that hypoxia was not an effective stimulant of VEGF production. However, it was reported that ALS patients in respiratory distress showed a marked increase in VEGF level following noninvasive ventilation onset. This suggests that correction of hypoxia leads to higher activation of the hypoxia element response in the VEGF promoter by HIF-1. In addition, the same authors found that VEGF plasma level increased strikingly in some ALS patients undergoing exercise [240]. Interestingly, an increased expression of VEGF mRNA with exercise has been demonstrated in muscle of normal exercising mice [245].

A correct evaluation of the results from the above studies should consider some methodological issues, namely: limited number of ALS patients and controls included; low sensitivity of the ELISA kit used; possible influence on the results from the cycles of freezing and thawing of biological samples [246248].

An immunohistochemical study reported that VEGFR-2 immunostaining in neuropil was decreased in the spinal cord of ALS patients when compared to controls [210, 249]. These results reinforce the hypothesis that the reduction of the VEGF signaling may play a role in the pathogenesis of ALS [246].

\section{Therapeutical Potential of VEGF in ALS}

There is a great potential of VEGF treatment in ALS; Table 5 summarizes its potential routes for administration and delivery.

5.1. VEGF Gene and VEGF Protein Delivery in Central Nervous System (CNS). Several studies used rodent ALS models for therapeutic purposes. After intracerebroventricular administration of recombinant VEGF in mice with ALS, it was observed delayed disease onset and prolonged survival [211], but systemic administration was noneffective. It was demonstrated that VEGF injected in the intracerebroventricular space is able to be transported anterogradely to the brainstem and lumbar spinal neurons, hence preserving the neuromuscular junctions and improving functional outcome $[211,250]$. The intracerebroventricular administration of VEGF also induces the expression of GluR2 in the ventral spinal cord of rats, which demonstrates the protective effect of VEGF on motor neurons [251]. It was also shown that astrocytes are capable of protecting against excitotoxicity by inducing the expression of GluR2 on motor neurons, while this feature is not present in mSOD1 mice [252]. Motor neurons express lower levels of GluR2 subunit leaving them more vulnerable to AMPA receptor-mediated excitotoxicity [251, 253]. Administration of VEGF by intraperitoneal injections in $\mathrm{SOD} 1^{\mathrm{G} 93 \mathrm{~A}}$ transgenic mouse showed muscle weakness delay and prolonged survival in treated mice [254]. Intranasal administration of VEGF may provide an effective alternative. In one study, it was reported that after intranasal administration of VEGF in adult Sprague-Dawley rats, the highest tissue delivery was found in the trigeminal nerve, followed by the optic nerve, olfactory bulbs, olfactory tubercle, striatum, medulla, frontal cortex, midbrain, thalamus, hippocampus, and cerebellum [255].

Positive studies with VEGF were found in other studies, including one from Azzouz et al., which used a lentiviral vector pseudotyped with the rabies $G$ envelope protein (EIAV vectors). Intramuscular administration of the vector permitted its retrograde transportation to the motor neuron, resulting in slower disease progression of the SOD1 ${ }^{\mathrm{G} 93 \mathrm{~A}}$ mice model, even when treatment was started at the onset of paralysis [41]. A more recent study with SOD ${ }^{\mathrm{G} 93 \mathrm{~A}}$ mice injected with adeno-associated virus serotype 4 VEGF vector showed promising results. Intracerebroventricular injection of AAV4-VEGF-165 led to significant extension of survival $[198,256]$. By adenoviral vector it is possible to get an upregulation of VEGF expression indirectly and remotely delivered, through the use of a zinc finger protein. A study used engineered zinc-finger protein into a vector Ad-32Flag-Ep65 (AD-p65), allowing to upregulate the expression of endogenous VEGF (VEGF-ZFP) in a laryngeal nerve (RLN)-crush injury model. The mice injected with adenovirus engineered ZFP-VEGF presented improvement in nerve regeneration, which led to a more rapid recovery when compared to controls [257]. Kliem and colleagues used a plasmid encoding zinc finger transcription factor protein (ZFP-TF) engineered to induce VEGF expression in mSOD1 rat model. The plasmid was administered intramuscularly in the lateral and medial gastrocnemius muscles at 80 days of age (prior to initiation of motor neuron degeneration) and weekly for a period of 6 weeks. Unilateral intramuscular delivery of VEGF in engineered zinc finger transcription factor preserved ipsilateral hindlimb grip strength and rotarod improved performance when compared to controls. Once the therapy was directed only to a single muscle, the investigators observed no change relative to the weight and the onset of disease of the mice [258]. 
Using a mouse NSC34 motor neuron-like cell culture system, following administration of an adenovirus vector in cultures containing mutant SOD $1^{\mathrm{G} 93 \mathrm{~A}}$, VEGF increased neuronal survival. However, the pretreated cells with VEGF displayed a dose-dependent resistance to oxidative damage, with the activation of both MAPK and PI3K pathways. The protective effects were mediated via VEGF PI3K activity [215].

The role of receptors as therapeutic targets requires further investigation. In an experimental study, antisense oligodeoxynucleotides against the VEGFR-2 were administrated in mice subjected to hypoxia, which resulted in the loss of nearly $50 \%$ of the motor neurons. This study demonstrates the direct neuroprotective activity of VEGFR-2. Motor neurons are more susceptible to degeneration when inhibiting the activation of AKT and ERK pathways, under conditions of hypoxia [259].

\subsection{Role of VEGF: Use of Stem Cell Therapy in ALS}

5.2.1. Animal and Human Neural Stem Cells (NSCs). Neural stem cells (NSCs) have an intrinsic ability to "rescue" dysfunctional neurons and to stimulate preservation, remodeling, and/or regeneration of host-derived neural circuitry [260]. In a meta-analysis, Teng and colleagues evaluated the effects of therapy of mouse and human NSCs transplantation in mSOD1 mice. Only one injection resulted in an extensive and robust integration of donor cells in the lumbar cord. NSCs promoted an increase in the secretion of trophic factors that contributed to the survival motor neuron, by reducing inflammation and astrogliosis, related to trophic factors production. It was observed, in the mice model, improved motor performance and respiratory function, slower disease progression, and delayed-onset disease [260, 261].

After intrathecal administration of the NCSs engineered to overexpressing human VEGF gene (HB1.F3.VEGF) in SOD $1^{\mathrm{G} 93 \mathrm{~A}}$ mouse model, there was a delay in disease onset and the survival was prolonged without significant adverse effects when compared to control animals. Transplanted cells were found in the anterior horn and differentiated into motor neurons. The neuroprotective effect was achieved by the production of antiapoptotic proteins ( $\mathrm{Bcl}-2 \mathrm{and} \mathrm{Bcl}-\mathrm{XL}$ ) and molecules promoting cell survival and downregulating proapoptotic proteins (Caspase-3 and BAX) [262].

5.2.2. Human Mesenchymal Stem Cells (hMSCs). A study with single human mesenchymal stem cells (hMSCs) showed that transplantation of hMSCs had no beneficial effect in mSOD1 mice. However, multiple transplantations allowed decreased motor neuron loss, enhanced motor performance, and increased survival in mSOD1 mice, although only a restricted number of cells migrated into the lumbar spinal cord parenchyma [263].

In 2013, Krakora et al. used hMSCs expressing both GDNF (hMSC-GDNF) and VEGF (hMSC-VEGF) that were injected into SOD ${ }^{\mathrm{G} 93 \mathrm{~A}}$ rats, which slowed motor function loss, protected neuromuscular junctions (NMJs), and prolonged lifespan. A synergistic effect was found when using combined delivery of these factors, compared to the single administration of each of these neurotrophic factors [264].

5.2.3. Human Adipose-Derived MSCs Stem Cells. It was demonstrated that the soluble growth factors (VEGF, HGF, and IGF-1) released by human adipose-derived stem cells (hADSCs) on primary astrocytes cultured from SOD1 ${ }^{\text {G93A }}$ mice significantly upregulate the expression of astrocytes GLT1 [265]. Marconi et al. demonstrated that the systemic injection of ADSCs in mSOD1 mice delayed disease onset and slowed deterioration of motor performance. This and other studies reinforce the idea that ADSCs can produce a number of neurotrophic factors (VEGF and IGF-1) capable of supporting neuronal survival [266-268].

5.2.4. Bone Marrow Stem Cells. Corti and colleagues evaluated the effect of cell therapy using intravascular injection of C-kit $(+)$ stem/progenitor cells in the spinal cord of SOD $1^{\mathrm{G} 93 \mathrm{~A}}$ mice. The transplanted stem cells caused a delay in disease progression, prolonged lifespan, promoted survival of motor neurons, and improved neuromuscular function. Neuroprotection resulted partially from the preservation of glutamate transporter GLT-1 levels, reduction of microgliosis, and increase of VEGF and angiopoietin $2[269,270]$.

A study was performed using genetically modified blood mononuclear cells from human umbilical cord blood (HUCB). They were transiently transfected by electroporation with VEGF-A in SOD1 ${ }^{\mathrm{G} 93 \mathrm{~A}}$ mice. These cells were retroorbitally administered via injection in presymptomatic phase (22-25 weeks). The results showed a differentiation of transplanted cells HUCB in vascular ECs and an increased survival of motor neuron in these mice [271].

\section{Use of VEGF in ALS Patients}

Trials testing VEGF for the treatment of neurodegenerative diseases, including ALS, have been considered after some positive experimental studies in animal models. Regarding human studies, it is crucial to evaluate safety. Particular care should be taken regarding complex VEGF effects on angiogenesis, inflammation, and capillary permeability [167, $221,272,273]$. A critical problem is to define a treatment window of VEGF in humans, taking into account that in SOD ${ }^{\text {G93A }}$ mice ICV administration at a dosage of $0.2 \mu \mathrm{g}$ VEGF. $\mathrm{kg}^{-1} \cdot$ day $^{-1}$ a day conferred neuroprotection, without undesirable inflammatory or angiogenic effects $[90,211]$. Another therapeutic pathway to explore is VEGF-B, a factor with few angiogenic potential. Some studies have reported that it has a neuroprotective effect with higher potential security when compared to VEGF-A [220].

Another issue that deserves to be addressed is the emerging need for standardization of analytical procedures in various biological samples, when it becomes necessary to determine VEGF levels. Further technological advances for determining other VEGF isoforms and their receptors (namely VEGF-B) are necessary, with greater sensitivity than the conventional ELISA. 
The company NeuroNova $\mathrm{AB}$ has been sponsoring clinical tests to develop a therapy based on direct intracerebroventricular administration of $\mathrm{VEGF}_{165}$ in ALS patients (by means of an FDA-approved and CE-marked pump and a specialized catheter for protein drug delivery directly into the brain by ICV infusion, sNN0029). Following the phase-1 trial (NCT00800501, a double-blind, randomised, parallel group safety and tolerability study), there is an open label safety and tolerability continuation study to further evaluate safety and tolerability, as well as motor function and survival in patients who participated in the previous study (NCT01384162).

A phase-2 trial in ALS patients is sponsored by Sangamo BioSciences (NCT00748501)_Clinical Trial of SB-509 in Subjects with Amyotrophic Lateral Sclerosis (ALS). Sangamo's drug, SB-509, is an injectable formulation of a plasmid encoding a zinc finger DNA-binding protein transcription factor (ZFP TF(TM)-Sangamo BioSciences) designed to upregulate the expression of the gene encoding VEGF-A. It was designed as a randomized repeat-dosing, open-label, multicenter trial to evaluate the effect of intramuscular administration of SB509 on the progression of the disease, as measured by the ALS Functional Rating Scale-Revised (ALSFRS-R). ALSFRS-R is a validated rating instrument for monitoring the progression of disability in patients with ALS. In addition to gathering data on safety and tolerability of SB-509 in ALS patients, data will be collected to evaluate the effect of SB-509 on additional clinical measures, forced vital capacity, neurophysiologic index [274], manual muscle test, and survival. The study is completed but no results have been released.

A randomized, blinded trial of intramuscular gene transfer using plasmid VEGF to treat diabetic polyneuropathy was done [275]. Thirty-nine diabetic patients with polyneuropathy were randomized to receive a VEGF-to-placebo ratio of $3: 1$. Three sets of injections were given at eight standardized sites adjacent to the sciatic, peroneal, and tibial nerves of one leg. Primary outcomes were changes in symptom score at 6 months and a prespecified overall clinical and electrophysiological improvement score. Intramuscular plasmid VEGF gene transfer tended to improve primary outcome, without major safety issues. The possibility to translate this approach to ALS patients is an open issue.

Further studies should be considered to test the use of stem cells combined with neurotrophic factors, as it seems to be a potential therapy for ALS. Those studies should be carried out under strict monitoring, thereby ensuring that the therapy is safe in humans.

Although VEGF is a very promising compound, there is a major challenge ahead that is to translate the basic science breakthroughs into clinical practice.

\section{Concluding Remarks}

No effective treatment able to stop disease progression is available for ALS. A large number of conventional trials have been negative, involving drugs with quite different properties. More challenging steps are necessary, testing breakthrough compounds and using more advanced methods for drug delivery.
The history of VEGF in medicine is not long but is rich and complex. The emerging evidence regarding the roles of this neurotrophic factor provides a strong rational for testing VEGF in neurodegenerative disorders. The future has started already and preliminary tests on the potential therapeutic efficacy of VEGF have been tested in patients with ALS. The future will show the right track, or at least the wrong ones. Anyway, it is relevant for the ALS community to know more on VEGF.

\section{Conflict of Interests}

The authors declare that there is no conflict of interests regarding the publication of this paper.

\section{References}

[1] K. E. Morrison and A. E. Harding, "Disorders of the motor neurone," Bailliere's Clinical Neurology, vol. 3, no. 2, pp. 431-445, 1994.

[2] P. Pasinelli and R. H. Brown, "Molecular biology of amyotrophic lateral sclerosis: insights from genetics," Nature Reviews Neuroscience, vol. 7, no. 9, pp. 710-723, 2006.

[3] Y. Wang, O. M. Xiao, L. Xie et al., "Vascular endothelial growth factor overexpression delays neurodegeneration and prolongs survival in amyotrophic lateral sclerosis mice," Journal of Neuroscience, vol. 27, no. 2, pp. 304-307, 2007.

[4] L. I. Bruijn, T. M. Miller, and D. W. Cleveland, "Unraveling the mechanisms involved in motor neuron degeneration in ALS," Annual Review of Neuroscience, vol. 27, pp. 723-749, 2004.

[5] L. C. Wijesekera and P. N. Leigh, "Amyotrophic lateral sclerosis," Orphanet Journal of Rare Diseases, vol. 4, no. 1, article 3, 2009.

[6] J. Costa, C. Gomes, and M. de Carvalho, "Diagnosis, pathogenesis and therapeutic targets in amyotrophic lateral sclerosis," CNS and Neurological Disorders-Drug Targets, vol. 9, no. 6, pp. 764778, 2010.

[7] L. Ferraiuolo, J. Kirby, A. J. Grierson, M. Sendtner, and P. J. Shaw, "Molecular pathways of motor neuron injury in amyotrophic lateral sclerosis," Nature Reviews Neurology, vol. 7, no. 11, pp. 616-630, 2011.

[8] D. W. Cleveland and J. D. Rothstein, "From Charcot to Lou Gehrig: deciphering selective motor neuron death in ALS," Nature Reviews Neuroscience, vol. 2, no. 11, pp. 806-819, 2001.

[9] W. Robberecht and T. Philips, "The changing scene of amyotrophic lateral sclerosis," Nature Reviews Neuroscience, vol. 14, no. 4, pp. 248-264, 2013.

[10] R. Daroff, G. Fenichel, J. Jankovic, and J. Mazziotta, "Disorders of upper and lower motor neurons," in Bradley's Neurology in Clinical Practice, Chapter 72, pp. 1855-1889, 6th edition, 2012.

[11] C. Bendotti, M. Marino, C. Cheroni et al., "Dysfunction of constitutive and inducible ubiquitin-proteasome system in amyotrophic lateral sclerosis: implication for protein aggregation and immune response," Progress in Neurobiology, vol. 97, no. 2, pp. 101-126, 2012.

[12] M. R. Turner, O. Hardiman, M. Benatar et al., "Controversies and priorities in amyotrophic lateral sclerosis," The Lancet Neurology, vol. 12, no. 3, pp. 310-322, 2013.

[13] A. Nalini, K. Thennarasu, M. Gourie-Devi, S. Shenoy, and D. Kulshreshtha, "Clinical characteristics and survival pattern of 1153 patients with amyotrophic lateral sclerosis: experience over 
30 years from India," Journal of the Neurological Sciences, vol. 272, no. 1-2, pp. 60-70, 2008.

[14] R. Daroff, G. Fenichel, J. Jankovic, and J. Mazziotta, "Disorders of upper and lower motor neurons," in Bradley's Neurology in Clinical Practice, Chapter 72, pp. 1855-1889, 6th edition, 2012.

[15] O. Hardiman, L. H. Van Den Berg, and M. C. Kiernan, "Clinical diagnosis and management of amyotrophic lateral sclerosis," Nature Reviews Neurology, vol. 7, no. 11, pp. 639-649, 2011.

[16] D. R. Rosen, T. Siddique, D. Patterson et al., "Mutations in $\mathrm{Cu} / \mathrm{Zn}$ superoxide dismutase gene are associated with familial amyotrophic lateral sclerosis," Nature, vol. 362, no. 6415, pp. 5962, 1993.

[17] P. M. Andersen and A. Al-Chalabi, "Clinical genetics of amyotrophic lateral sclerosis: what do we really know?" Nature Reviews Neurology, vol. 7, no. 11, pp. 603-615, 2011.

[18] S. Hadano, C. K. Hand, H. Osuga et al., "A gene encoding a putative GTPase regulator is mutated in familial amyotrophic lateral sclerosis 2," Nature Genetics, vol. 29, pp. 166-173, 2001.

[19] Y. Yang, A. Hentati, H.-X. Deng et al., "The gene encoding alsin, a protein with three guanine-nucleotide exchange factor domains, is mutated in a form of recessive amyotrophic lateral sclerosis," Nature Genetics, vol. 29, no. 2, pp. 160-165, 2001.

[20] Y.-Z. Chen, C. L. Bennett, H. M. Huynh et al., "DNA/RNA helicase gene mutations in a form of juvenile amyotrophic lateral sclerosis (ALS4)," American Journal of Human Genetics, vol. 74, no. 6, pp. 1128-1135, 2004.

[21] A. L. Nishimura, M. Mitne-Neto, H. C. A. Silva et al., "A mutation in the vesicle-trafficking protein VAPB causes lateonset spinal muscular atrophy and amyotrophic lateral sclerosis," American Journal of Human Genetics, vol. 75, no. 5, pp. 822831, 2004.

[22] M. J. Greenway, M. D. Alexander, S. Ennis et al., "A novel candidate region for ALS on chromosome 14q11.2," Neurology, vol. 63, no. 10, pp. 1936-1938, 2004.

[23] M. J. Greenway, P. M. Andersen, G. Russ et al., "ANG mutations segregate with familial and "sporadic" amyotrophic lateral sclerosis," Nature Genetics, vol. 38, no. 4, pp. 411-413, 2006.

[24] M. Neumann, D. M. Sampathu, L. K. Kwong et al., "Ubiquitinated TDP-43 in frontotemporal lobar degeneration and amyotrophic lateral sclerosis," Science, vol. 314, no. 5796, pp. 130-133, 2006.

[25] C. Vance, B. Rogelj, T. Hortobágyi et al., "Mutations in FUS, an RNA processing protein, cause familial amyotrophic lateral sclerosis type 6," Science, vol. 323, no. 5918, pp. 1208-1211, 2009.

[26] T. J. Kwiatkowski Jr., D. A. Bosco, A. L. LeClerc et al., "Mutations in the FUS/TLS gene on chromosome 16 cause familial amyotrophic lateral sclerosis," Science, vol. 323, no. 5918, pp. 12051208, 2009.

[27] H. Maruyama, H. Morino, H. Ito et al., "Mutations of optineurin in amyotrophic lateral sclerosis," Nature, vol. 465, no. 7295, pp. 223-226, 2010.

[28] H. T. Orr, "FTD and ALS: genetic ties that bind," Neuron, vol. 72, no. 2, pp. 189-190, 2011.

[29] M. DeJesus-Hernandez, I. R. Mackenzie, B. F. Boeve et al., "Expanded GGGGCC hexanucleotide repeat in noncoding region of C9ORF72 causes chromosome 9p-linked FTD and ALS," Neuron, vol. 72, no. 2, pp. 245-256, 2011.

[30] A. E. Renton, E. Majounie, A. Waite et al., "A hexanucleotide repeat expansion in C9ORF72 is the cause of chromosome 9p21linked ALS-FTD," Neuron, vol. 72, no. 2, pp. 257-268, 2011.
[31] C. Ingre, S. Pinto, A. Birve et al., "No association between VAPB mutations and familial or sporadic ALS in Sweden, Portugal and Iceland," in Amyotrophic Lateral Sclerosis and Frontotemporal Degeneration, vol. 14, pp. 620-627, 2013.

[32] M. van Blitterswijk, M. A. van Es, E. A. Hennekam et al., "Evidence for a polygenic basis of amyotrophic lateral sclerosis," in Complexity of Familial Amyotrophic Lateral Sclerosis, p. 135, 2012.

[33] J. Andrews, "Amyotrophic lateral sclerosis: clinical management and research update," Current Neurology and Neuroscience Reports, vol. 9, no. 1, pp. 59-68, 2009.

[34] R. G. Miller, J. D. Mitchell, M. Lyon, and D. H. Moore, "Riluzole for amyotrophic lateral sclerosis (ALS)/motor neuron disease (MND)," Cochrane Database of Systematic Reviews, no. 1, Article ID CD001447, 2007.

[35] M. de Carvalho, J. Costa, and M. Swash, "Clinical trials in ALS: a review of the role of clinical and neurophysiological measurements," Amyotrophic Lateral Sclerosis and Other Motor Neuron Disorders, vol. 6, no. 1, pp. 202-212, 2005.

[36] B. Oosthuyse, L. Moons, E. Storkebaum et al., "Deletion of the hypoxia-response element in the vascular endothelial growth factor promoter causes motor neuron degeneration," Nature Genetics, vol. 28, no. 2, pp. 131-138, 2001.

[37] K. L. Jin, X. O. Mao, and D. A. Greenberg, "Vascular endothelial growth factor: direct neuroprotective effect in in vitro ischemia," Proceedings of the National Academy of Sciences of the United States of America, vol. 97, no. 18, pp. 10242-10247, 2000.

[38] K. L. Jin, X. O. Mao, T. Nagayama, P. C. Goldsmith, and D. A. Greenberg, "Induction of vascular endothelial growth factor receptors and phosphatidylinositol 3'-kinase/Akt signaling by global cerebral ischemia in the rat," Neuroscience, vol. 100, no. 4, pp. 713-717, 2000

[39] W. F. Silverman, J. M. Krum, N. Mani, and J. M. Rosenstein, "Vascular, glial and neuronal effects of vascular endothelial growth factor in mesencephalic explant cultures," Neuroscience, vol. 90, no. 4, pp. 1529-1541, 1999.

[40] D. Lambrechts, E. Storkebaum, M. Morimoto et al., "VEGF is a modifier of amyotrophic lateral sclerosis in mice and humans and protects motoneurons against ischemic death," Nature Genetics, vol. 34, no. 4, pp. 383-394, 2003.

[41] M. Azzouz, G. S. Ralph, E. Storkebaum et al., "VEGF delivery with retrogradely transported lentivector prolongs survival in a mouse ALS model," Nature, vol. 429, no. 6990, pp. 413-417, 2004.

[42] E. Storkebaum and P. Carmeliet, "VEGF: a critical player in neurodegeneration," Journal of Clinical Investigation, vol. 113, no. 1, pp. 14-18, 2004.

[43] E. Storkebaum, D. Lambrechts, and P. Carmeliet, "VEGF: once regarded as a specific angiogenic factor, now implicated in neuroprotection," BioEssays, vol. 26, no. 9, pp. 943-954, 2004.

[44] D. W. Leung, G. Cachianes, W.-J. Kuang, D. V. Goeddel, and N. Ferrara, "Vascular endothelial growth factor is a secreted angiogenic mitogen," Science, vol. 246, no. 4935, pp. 1306-1309, 1989.

[45] N. Ferrara, "Vascular endothelial growth factor as a target for anticancer therapy," Oncologist, vol. 9, no. 1, pp. 2-10, 2004.

[46] N. Ferrara, "Vascular endothelial growth factor: basic science and clinical progress," Endocrine Reviews, vol. 25, no. 4, pp. 581611, 2004.

[47] H. F. Dvorak, L. F. Brown, M. Detmar, and A. M. Dvorak, "Vascular permeability factor/vascular endothelial growth factor, 
microvascular hyperpermeability, and angiogenesis," American Journal of Pathology, vol. 146, no. 5, pp. 1029-1039, 1995.

[48] C. Ruhrberg, "Growing and shaping the vascular tree: multiple roles for VEGF”, BioEssays, vol. 25, no. 11, pp. 1052-1060, 2003.

[49] H. Takahashi and M. Shibuya, "The vascular endothelial growth factor (VEGF)/VEGF receptor system and its role under physiological and pathological conditions," Clinical Science, vol. 109, no. 3, pp. 227-241, 2005.

[50] A. Hoeben, B. Landuyt, M. S. Highley, H. Wildiers, A. T. Van Oosterom, and E. A. De Bruijn, "Vascular endothelial growth factor and angiogenesis," Pharmacological Reviews, vol. 56, no. 4, pp. 549-580, 2004.

[51] V. Vincenti, C. Cassano, M. Rocchi, and M. G. Persico, "Assignment of the vascular endothelial growth factor gene to human chromosome 6p21.3," Circulation, vol. 93, no. 8, pp. 1493-1495, 1996.

[52] N. Ferrara, H.-P. Gerber, and J. LeCouter, "The biology of VEGF and its receptors," Nature Medicine, vol. 9, no. 6, pp. 669-676, 2003.

[53] A.-K. Olsson, A. Dimberg, J. Kreuger, and L. Claesson-Welsh, "VEGF receptor signalling-in control of vascular function," Nature Reviews Molecular Cell Biology, vol. 7, no. 5, pp. 359-371, 2006.

[54] K. A. Houck, N. Ferrara, J. Winer, G. Cachianes, B. Li, and D. W. Leung, "The vascular endothelial growth factor family: identification of a fourth molecular species and characterization of alternative splicing of RNA," Molecular Endocrinology, vol. 5, no. 12, pp. 1806-1814, 1991.

[55] E. Bogaert, P. Van Damme, L. Van Den Bosch, and W. Robberecht, "Vascular endothelial growth factor in amyotrophic lateral sclerosis and other neurodegenerative diseases," Muscle and Nerve, vol. 34, no. 4, pp. 391-405, 2006.

[56] R. Roskoski Jr., "Vascular endothelial growth factor (VEGF) signaling in tumor progression," Critical Reviews in Oncology/Hematology, vol. 62, no. 3, pp. 179-213, 2007.

[57] P. M. Biselli-Chicote, A. R. Oliveira, E. C. Pavarino, and E. M. Goloni-Bertollo, "VEGF gene alternative splicing: pro- and anti-angiogenic isoforms in cancer," Journal of Cancer Research and Clinical Oncology, vol. 138, no. 3, pp. 363-370, 2012.

[58] T. Falk, R. T. Gonzalez, and S. J. Sherman, "The Yin and Yang of VEGF and PEDF: multifaceted neurotrophic factors and their potential in the treatment of Parkinson's disease," International Journal of Molecular Sciences, vol. 11, no. 8, pp. 2875-2900, 2010.

[59] D. Maglione, V. Guerriero, G. Viglietto, P. Delli-Bovi, and M. G. Persico, "Isolation of a human placenta cDNA coding for a protein related to the vascular permeability factor," Proceedings of the National Academy of Sciences of the United States of America, vol. 88, no. 20, pp. 9267-9271, 1991.

[60] M. Persico, V. Vincenti, and T. DiPalma, "Structure, expression and receptor-binding properties of placenta growth factor (PlGF)," in Vascular Growth Factors and Angiogenesis, Current Topics in Microbiology and Immunology, pp. 31-40, Springer, 1999.

[61] M. Autiero, J. Waltenberger, D. Communi et al., "Role of PlGF in the intra- and intermolecular cross talk between the VEGF receptors Flt1 and Flk1," Nature Medicine, vol. 9, no. 7, pp. 936943, 2003.

[62] J. E. Park, H. H. Chen, J. Winer, K. A. Houck, and N. Ferrara, "Placenta growth factor. Potentiation of vascular endothelial growth factor bioactivity, in vitro and in vivo, and high affinity binding to Flt-1 but not to Flk-1/KDR," Journal of Biological Chemistry, vol. 269, no. 41, pp. 25646-25654, 1994.
[63] H. Roy, S. Bhardwaj, and S. Ylä-Herttuala, "Biology of vascular endothelial growth factors," FEBS Letters, vol. 580, no. 12, pp. 2879-2887, 2006.

[64] S. De Falco, B. Gigante, and M. G. Persico, "Structure and function of placental growth factor," Trends in Cardiovascular Medicine, vol. 12, no. 6, pp. 241-246, 2002.

[65] N. Ferrara and T. Davis-Smyth, "The biology of vascular endothelial growth factor," Endocrine Reviews, vol. 18, no. 1, pp. 4-25, 1997.

[66] S. Grimmond, J. Lagercrantz, C. Drinkwater et al., "Cloning and characterization of a novel human gene related to vascular endothelial growth factor," Genome Research, vol. 6, no. 2, pp. 124-131, 1996.

[67] K. Paavonen, N. Horelli-Kuitunen, D. Chilov et al., "Novel human vascular endothelial growth factor genes VEGF-B and VEGF-C localize to chromosomes 11q13 and 4q34, respectively," Circulation, vol. 93, no. 6, pp. 1079-1082, 1996.

[68] P. Salven, A. Lymboussaki, P. Heikkilä et al., "Vascular endothelial growth factors VEGF-B and VEGF-C are expressed in human tumors," American Journal of Pathology, vol. 153, no. 1, pp. 103-108, 1998.

[69] X. Li, A. Kumar, C. Lee et al., "Can VEGF-B be used to treat neurodegenerative diseases?" in Neurodegenerative Diseases Processes, Prevention, Protection and Monitoring, 2011.

[70] T. Tammela, B. Enholm, K. Alitalo, and K. Paavonen, "The biology of vascular endothelial growth factors," Cardiovascular Research, vol. 65, no. 3, pp. 550-563, 2005.

[71] B. Enholm, K. Paavonen, A. Ristimäki et al., "Comparison of VEGF, VEGF-B, VEGF-C and Ang-1 mRNA regulation by serum, growth factors, oncoproteins and hypoxia," Oncogene, vol. 14, no. 20, pp. 2475-2483, 1997.

[72] B. Olofsson, M. Jeltsch, U. Eriksson, and K. Alitalo, "Current biology of VEGF-B and VEGF-C," Current Opinion in Biotechnology, vol. 10, no. 6, pp. 528-538, 1999.

[73] X. Li, M. Tjwa, I. Van Hove et al., "Reevaluation of the role of VEGF-B suggests a restricted role in the revascularization of the ischemic myocardium," Arteriosclerosis, Thrombosis, and Vascular Biology, vol. 28, no. 9, pp. 1614-1620, 2008.

[74] K. Aase, A. Lymboussaki, A. Kaipainen, B. Olofsson, K. Alitalo, and U. Eriksson, "Localization of VEGF-B in the mouse embryo suggests a paracrine role of the growth factor in the developing vasculature," Developmental Dynamics, vol. 215, no. 1, pp. 12-25, 1999.

[75] Y. Yamada, J.-I. Nezu, M. Shimane, and Y. Hirata, "Molecular cloning of a novel vascular endothelial growth factor, VEGF-D," Genomics, vol. 42, no. 3, pp. 483-488, 1997.

[76] S.-J. Oh, M. M. Jeltsch, R. Birkenhäger et al., "VEGF and VEGF$\mathrm{C}$ : specific induction of angiogenesis and lymphangiogenesis in the differentiated avian chorioallantoic membrane," Developmental Biology, vol. 188, no. 1, pp. 96-109, 1997.

[77] M. Jeltsch, A. Kaipainen, V. Joukov et al., "Hyperplasia of lymphatic vessels in VEGF-C transgenic mice," Science, vol. 276, no. 5317, pp. 1423-1425, 1997.

[78] T. T. Rissanen, J. E. Markkanen, M. Gruchala et al., "VEGF$\mathrm{D}$ is the strongest angiogenic and lymphangiogenic effector among VEGFs delivered into skeletal muscle via adenoviruses," Circulation Research, vol. 92, no. 10, pp. 1098-1106, 2003.

[79] M. G. Achen, B. K. McColl, and S. A. Stacker, "Focus on lymphangiogenesis in tumor metastasis," Cancer Cell, vol. 7, no. 2, pp. 121-127, 2005. 
[80] T. Tammela, G. Zarkada, E. Wallgard et al., "Blocking VEGFR-3 suppresses angiogenic sprouting and vascular network formation," Nature, vol. 454, no. 7204, pp. 656-660, 2008.

[81] M. Shibuya, "Vascular endothelial growth factor-dependent and-independent regulation of angiogenesis," Angiogenesis, vol. 12, p. 15, 2008.

[82] M. G. Achen and S. A. Stacker, "Vascular endothelial growth factor-D: signaling mechanisms, biology, and clinical relevance," Growth Factors, vol. 30, no. 5, pp. 283-296, 2012.

[83] P. Saharinen, T. Tammela, M. J. Karkkainen, and K. Alitalo, "Lymphatic vasculature: development, molecular regulation and role in tumor metastasis and inflammation," Trends in Immunology, vol. 25, no. 7, pp. 387-395, 2004.

[84] M. Lohela, A. Saaristo, T. Veikkola, and K. Alitalo, "Lymphangiogenic growth factors, receptors and therapies," Thrombosis and Haemostasis, vol. 90, no. 2, pp. 167-184, 2003.

[85] V. Joukov, K. Pajusola, A. Kaipainen et al., "A novel vascular endothelial growth factor, VEGF-C, is a ligand for the Flt4 (VEGFR-3) and KDR (VEGFR-2) receptor tyrosine kinases," EMBO Journal, vol. 15, no. 2, pp. 290-298, 1996.

[86] M. Meyer, M. Clauss, A. Lepple-Wienhues et al., "A novel vascular endothelial growth factor encoded by Orf virus, VEGF-E, mediates angiogenesis via signalling through VEGFR2 (KDR) but not VEGFR-1 (Flt-1) receptor tyrosine kinases," EMBO Journal, vol. 18, no. 2, pp. 363-374, 1999.

[87] I. D. L. M. Junqueira de Azevedo, S. H. Poliselli Farsky, M. L. S. Oliveira, and P. L. Ho, "Molecular cloning and expression of a functional snake venom vascular endothelium growth factor (VEGF) from the Bothrops insularis pit viper: a new member of the VEGF family of proteins," Journal of Biological Chemistry, vol. 276, no. 43, pp. 39836-39842, 2001.

[88] N. Ferrara, "VEGF and Its Receptors," in VEGF and Cancer, Chapter 1, pp. 2-11, 2004.

[89] B. I. Terman, M. E. Carrion, E. Kovacs, B. A. Rasmussen, R. L. Eddy, and T. B. Shows, "Identification of a new endothelial cell growth factor receptor tyrosine kinase," Oncogene, vol. 6, no. 9, pp. 1677-1683, 1991.

[90] C. R. De Almodovar, D. Lambrechts, M. Mazzone, and P. Carmeliet, "Role and therapeutic potential of VEGF in the nervous system," Physiological Reviews, vol. 89, no. 2, pp. 607648, 2009.

[91] K. Alitalo and P. Carmeliet, "Molecular mechanisms of lymphangiogenesis in health and disease," Cancer Cell, vol. 1, no. 3, pp. 219-227, 2002.

[92] M. Shibuya, "Differential roles of vascular endothelial growth factor receptor-1 and receptor-2 in angiogenesis," Journal of Biochemistry and Molecular Biology, vol. 39, no. 5, pp. 469-478, 2006.

[93] H. Satoh, M. Yoshida, and H. Matsushime, "Regional localization of the human c-ros-1 on 6q22 and flt on 13q12," Japanese Journal of Cancer Research, vol. 78, no. 8, pp. 772-775, 1987.

[94] I. Zachary and G. Gliki, "Signaling transduction mechanisms mediating biological actions of the vascular endothelial growth factor family," Cardiovascular Research, vol. 49, no. 3, pp. 568$581,2001$.

[95] H.-P. Gerber, F. Condorelli, J. Park, and N. Ferrara, "Differential transcriptional regulation of the two vascular endothelial growth factor receptor genes. Flt-1, but not Flk-1/KDR, is upregulated by hypoxia," Journal of Biological Chemistry, vol. 272, no. 38 , pp. $23659-23667,1997$.
[96] R. L. Kendall and K. A. Thomas, "Inhibition of vascular endothelial cell growth factor activity by an endogenously encoded soluble receptor," Proceedings of the National Academy of Sciences of the United States of America, vol. 90, no. 22, pp. 10705-10709, 1993.

[97] R. J. Levine, S. E. Maynard, C. Qian et al., "Circulating angiogenic factors and the risk of preeclampsia," The New England Journal of Medicine, vol. 350, no. 7, pp. 672-683, 2004.

[98] R. Thadhani, W. P. Mutter, M. Wolf et al., "First trimester placental growth factor and soluble fms-like tyrosine kinase 1 and risk for preeclampsia," Journal of Clinical Endocrinology and Metabolism, vol. 89, no. 2, pp. 770-775, 2004.

[99] S. N. J. Sait, M. Dougher-Vermazen, T. B. Shows, and B. I. Terman, "The kinase insert domain receptor gene (KDR) has been relocated to chromosome $4 \mathrm{q} 11 \rightarrow \mathrm{q} 12$," Cytogenetics and Cell Genetics, vol. 70, no. 1-2, pp. 145-146, 1995.

[100] H. Gille, J. Kowalski, B. Li et al., "Analysis of biological effects and signaling properties of Flt-1 (VEGFR-1) and KDR (VEGFR-2): a reassessment using novel receptor-specific vascular endothelial growth factor mutants," Journal of Biological Chemistry, vol. 276, no. 5, pp. 3222-3230, 2001.

[101] I. Zachary, "Vascular endothelial growth factor: how it transmits its signal," Experimental Nephrology, vol. 6, no. 6, pp. 480487, 1998.

[102] M. Sondell, G. Lundborg, and M. Kanje, "Vascular endothelial growth factor has neurotrophic activity and stimulates axonal outgrowth, enhancing cell survival and Schwann cell proliferation in the peripheral nervous system," Journal of Neuroscience, vol. 19, no. 14, pp. 5731-5740, 1999.

[103] K. Jin, Y. Zhu, Y. Sun, X. O. Mao, L. Xie, and D. A. Greenberg, "Vascular endothelial growth factor (VEGF) stimulates neurogenesis in vitro and in vivo," Proceedings of the National Academy of Sciences of the United States of America, vol. 99, no. 18, pp. 11946-11950, 2002.

[104] F. Shalaby, J. Rossant, T. P. Yamaguchi et al., "Failure of bloodisland formation and vasculogenesis in Flk-1 deficient mice," Nature, vol. 376, no. 6535, pp. 62-66, 1995.

[105] S. Hiratsuka, O. Minowa, J. Kuno, T. Noda, and M. Shibuya, "Flt-1 lacking the tyrosine kinase domain is sufficient for normal development and angiogenesis in mice," Proceedings of the National Academy of Sciences of the United States of America, vol. 95, no. 16, pp. 9349-9354, 1998.

[106] M. Shibuya and L. Claesson-Welsh, "Signal transduction by VEGF receptors in regulation of angiogenesis and lymphangiogenesis," Experimental Cell Research, vol. 312, no. 5, pp. 549-560, 2006.

[107] M. G. Achen, M. Jeltsch, E. Kukk et al., "Vascular endothelial growth factor D (VEGF-D) is a ligand for the tyrosine kinases VEGF receptor 2 (Flk1) and VEGF receptor 3 (Flt4)," Proceedings of the National Academy of Sciences of the United States of America, vol. 95, no. 2, pp. 548-553, 1998.

[108] K. Pajusola, O. Aprelikova, G. Pelicci, H. Weich, L. ClaessonWelsh, and K. Alitalo, "Signalling properties of FLT4, a proteolytically processed receptor tyrosine kinase related to two VEGF receptors," Oncogene, vol. 9, no. 12, pp. 3545-3555, 1994.

[109] S. Cébe-Suarez, A. Zehnder-Fjällman, and K. Ballmer-Hofer, "The role of VEGF receptors in angiogenesis; complex partnerships," Cellular and Molecular Life Sciences, vol. 63, no. 5, pp. 601-615, 2006.

[110] A. Kaipainen, J. Korhonen, T. Mustonen et al., "Expression of the fms-like tyrosine kinase 4 gene becomes restricted to 
lymphatic endothelium during development," Proceedings of the National Academy of Sciences of the United States of America, vol. 92, no. 8, pp. 3566-3570, 1995.

[111] S. Koch and L. Claesson-Welsh, "Signal transduction by vascular endothelial growth factor receptors," Cold Spring Harbor Perspectives in Medicine, vol. 2, no. 7, Article ID a006502, 2012.

[112] J. Lee, A. Gray, J. Yuan, S.-M. Luoh, H. Avraham, and W. I. Wood, "Vascular endothelial growth factor-related protein: a ligand and specific activator of the tyrosine kinase receptor Flt4," Proceedings of the National Academy of Sciences of the United States of America, vol. 93, no. 5, pp. 1988-1992, 1996.

[113] B. Le Bras, M.-J. Barallobre, J. Homman-Ludiye et al., "VEGF$\mathrm{C}$ is a trophic factor for neural progenitors in the vertebrate embryonic brain," Nature Neuroscience, vol. 9, no. 3, pp. 340348, 2006.

[114] K. Hamada, Y. Oike, N. Takakura et al., "VEGF-C signaling pathways through VEGFR-2 and VEGFR-3 in vasculoangiogenesis and hematopoiesis," Blood, vol. 96, no. 12, pp. 3793-3800, 2000.

[115] D. J. Dumont, L. Jussila, J. Taipale et al., "Cardiovascular failure in mouse embryos deficient in VEGF receptor-3," Science, vol. 282, no. 5390, pp. 946-949, 1998.

[116] M. Klagsbrun, S. Takashima, and R. Mamluk, "The role of neuropilin in vascular and tumor biology," Advances in Experimental Medicine and Biology, vol. 515, pp. 33-48, 2002.

[117] G. Neufeld, T. Cohen, N. Shraga, T. Lange, O. Kessler, and Y. Herzog, "The neuropilins: multifunctional semaphorin and VEGF receptors that modulate axon guidance and angiogenesis," Trends in Cardiovascular Medicine, vol. 12, no. 1, pp. 13-19, 2002.

[118] G. Neufeld, O. Kessler, and Y. Herzog, "The interaction of neuropilin-1 and neurropilin-2 with tyrosine-kinase receptors for VEGF," Advances in Experimental Medicine and Biology, vol. 515, pp. 81-90, 2002.

[119] S. Soker, S. Takashima, H. Q. Miao, G. Neufeld, and M. Klagsbrun, "Neuropilin-1 is expressed by endothelial and tumor cells as an isoform- specific receptor for vascular endothelial growth factor," Cell, vol. 92, no. 6, pp. 735-745, 1998.

[120] S. Soker, H.-Q. Miao, M. Nomi, S. Takashima, and M. Klagsbrun, "VEGF165 mediates formation of complexes containing VEGFR-2 and neuropilin-1 that enhance VEGF165-receptor binding," Journal of Cellular Biochemistry, vol. 85, no. 2, pp. 357$368,2002$.

[121] E. Geretti, A. Shimizu, and M. Klagsbrun, "Neuropilin structure governs VEGF and semaphorin binding and regulates angiogenesis," Angiogenesis, vol. 11, no. 1, pp. 31-39, 2008.

[122] A. Bagri and M. Tessier-Lavigne, "Neuropilins as Semaphorin receptors: in vivo functions in neuronal cell migration and axon guidance," Advances in Experimental Medicine and Biology, vol. 515, pp. 13-31, 2002.

[123] A. L. Kolodkin, D. V. Levengood, E. G. Rowe, Y.-T. Tai, R. J. Giger, and D. D. Ginty, "Neuropilin is a semaphorin III receptor," Cell, vol. 90, no. 4, pp. 753-762, 1997.

[124] T. Kitsukawa, A. Shimono, A. Kawakami, H. Kondoh, and H. Fujisawa, "Overexpression of a membrane protein, neuropilin, in chimeric mice causes anomalies in the cardiovascular system, nervous system and limbs," Development, vol. 121, no. 12, pp. 4309-4318, 1995.

[125] T. Kawasaki, T. Kitsukawa, Y. Bekku et al., "A requirement for neuropilin-1 in embryonic vessel formation," Development, vol. 126, no. 21, pp. 4895-4902, 1999.
[126] P. Lee, K. Goishi, A. J. Davidson, R. Mannix, L. Zon, and M. Klagsbrun, "Neuropilin-1 is required for vascular development and is a mediator of VEGF-dependent angiogenesis in zebrafish," Proceedings of the National Academy of Sciences of the United States of America, vol. 99, no. 16, pp. 10470-10475, 2002.

[127] L. Yuan, D. Moyon, L. Pardanaud et al., "Abnormal lymphatic vessel development in neuropilin 2 mutant mice," Development, vol. 129, no. 20, pp. 4797-4806, 2002.

[128] S. Takashima, M. Kitakaze, M. Asakura et al., "Targeting of both mouse neuropilin-1 and neuropilin-2 genes severely impairs developmental yolk sac and embryonic angiogenesis," Proceedings of the National Academy of Sciences of the United States of America, vol. 99, no. 6, pp. 3657-3662, 2002.

[129] K. Xie, D. Wei, Q. Shi, and S. Huang, "Constitutive and inducible expression and regulation of vascular endothelial growth factor," Cytokine and Growth Factor Reviews, vol. 15, no. 5, pp. 297-324, 2004.

[130] S. B. Krantz, “Erythropoietin,” Blood, vol. 77, no. 3, pp. 419-434, 1991.

[131] J. A. Forsythe, B.-H. Jiang, N. V. Iyer et al., "Activation of vascular endothelial growth factor gene transcription by hypoxiainducible factor 1," Molecular and Cellular Biology, vol. 16, no. 9, pp. 4604-4613, 1996.

[132] H. E. Ryan, M. Poloni, W. McNulty et al., "Hypoxia-inducible factor- $1 \alpha$ is a positive factor in solid tumor growth," Cancer Research, vol. 60, no. 15, pp. 4010-4015, 2000.

[133] P. H. Maxwell and P. J. Ratcliffe, "Oxygen sensors and angiogenesis," Seminars in Cell and Developmental Biology, vol. 13, no. 1, pp. 29-37, 2002.

[134] N. Ferrara and K. Alitalo, "Clinical applications of angiogenic growth factors and their inhibitors," Nature Medicine, vol. 5, no. 12, pp. 1359-1364, 1999.

[135] Y. Tsuzuki, D. Fukumura, B. Oosthuyse, C. Koike, P. Carmeliet, and R. K. Jain, "Vascular endothelial growth factor (VEGF) modulation by targeting hypoxia-inducible factor- $1 \alpha \rightarrow$ hypoxia response element $\rightarrow$ VEGF cascade differentially regulates vascular response and growth rate in tumors," Cancer Research, vol. 60, no. 22, pp. 6248-6252, 2000.

[136] H. F. Dvorak, "Vascular permeability factor/vascular endothelial growth factor: a critical cytokine in tumor angiogenesis and a potential target for diagnosis and therapy," Journal of Clinical Oncology, vol. 20, no. 21, pp. 4368-4380, 2002.

[137] G. Pagès and J. Pouysségur, "Transcriptional regulation of the Vascular Endothelial Growth Factor gene-a concert of activating factors," Cardiovascular Research, vol. 65, no. 3, pp. 564-573, 2005.

[138] G. L. Wang, B.-H. Jiang, E. A. Rue, and G. L. Semenza, "Hypoxia-inducible factor 1 is a basic-helix-loop-helix-PAS heterodimer regulated by cellular $\mathrm{O}_{2}$ tension," Proceedings of the National Academy of Sciences of the United States of America, vol. 92, no. 12, pp. 5510-5514, 1995.

[139] G. L. Wang and G. L. Semenza, "Purification and characterization of hypoxia-inducible factor 1," Journal of Biological Chemistry, vol. 270, no. 3, pp. 1230-1237, 1995.

[140] G. U. Dachs and G. M. Tozer, "Hypoxia modulated gene expression: angiogenesis, metastasis and therapeutic exploitation," European Journal of Cancer, vol. 36, no. 13, pp. 1649-1660, 2000.

[141] A. P. Levy, N. S. Levy, S. Wegner, and M. A. Goldberg, “Transcriptional regulation of the rat vascular endothelial growth factor gene by hypoxia," Journal of Biological Chemistry, vol. 270, no. 22, pp. 13333-13340, 1995. 
[142] S. Salceda and J. Caro, "Hypoxia-inducible factor $1 \alpha$ (HIF$1 \alpha$ ) protein is rapidly degraded by the ubiquitin-proteasome system under normoxic conditions. Its stabilization by hypoxia depends on redox-induced changes," Journal of Biological Chemistry, vol. 272, no. 36, pp. 22642-22647, 1997.

[143] C. W. Pugh and P. J. Ratcliffe, "Regulation of angiogenesis by hypoxia: role of the HIF system," Nature Medicine, vol. 9, no. 6, pp. 677-684, 2003.

[144] M. Ivan, K. Kondo, H. Yang et al., "HIF $\alpha$ targeted for VHLmediated destruction by proline hydroxylation: implications for $\mathrm{O}_{2}$ sensing," Science, vol. 292, no. 5516, pp. 464-468, 2001.

[145] G. L. Semenza, "HIF-1 and mechanisms of hypoxia sensing," Current Opinion in Cell Biology, vol. 13, no. 2, pp. 167-171, 2001.

[146] D. R. Mole, P. H. Maxwell, C. W. Pugh, and P. J. Ratcliffe, "Regulation of HIF by the von Hippel-Lindau tumour suppressor: implications for cellular oxygen sensing," IUBMB Life, vol. 52, no. 1-2, pp. 43-47, 2001.

[147] C. H. Sutter, E. Laughner, and G. L. Semenza, "Hypoxiainducible factor $1 \alpha$ protein expression is controlled by oxygenregulated ubiquitination that is disrupted by deletions and missense mutations," Proceedings of the National Academy of Sciences of the United States of America, vol. 97, no. 9, pp. 4748$4753,2000$.

[148] G. L. Semenza, "Defining the role of hypoxia-inducible factor 1 in cancer biology and therapeutics," Oncogene, vol. 29, no. 5, pp. 625-634, 2010

[149] G. Neufeld, T. Cohen, S. Gengrinovitch, and Z. Poltorak, "Vascular endothelial growth factor (VEGF) and its receptors," FASEB Journal, vol. 13, no. 1, pp. 9-22, 1999.

[150] P. Ben-Av, L. J. Crofford, R. L. Wilder, and T. Hla, "Induction of vascular endothelial growth factor expression in synovial fibroblasts by prostaglandin E and interleukin-1: a potential mechanism for inflammatory angiogenesis," FEBS Letters, vol. 372, no. 1, pp. 83-87, 1995.

[151] L. Pertovaara, A. Kaipainen, T. Mustonen et al., "Vascular endothelial growth factor is induced in response to transforming growth factor- $\beta$ in fibroblastic and epithelial cells," Journal of Biological Chemistry, vol. 269, no. 9, pp. 6271-6274, 1994.

[152] S.-I. Harada, J. A. Nagy, K. A. Sullivan et al., "Induction of vascular endothelial growth factor expression by prostaglandin E2 and E1 in osteoblasts," Journal of Clinical Investigation, vol. 93, no. 6, pp. 2490-2496, 1994.

[153] J. Li, M. A. Perrella, J.-C. Tsai et al., "Induction of vascular endothelial growth factor gene expression by interleukin- $1 \beta$ in rat aortic smooth muscle cells," Journal of Biological Chemistry, vol. 270, no. 1, pp. 308-312, 1995.

[154] T. Cohen, D. Nahari, L. W. Cerem, G. Neufeld, and B.-Z. Levin, "Interleukin 6 induces the expression of vascular endothelial growth factor," Journal of Biological Chemistry, vol. 271, no. 2, pp. 736-741, 1996.

[155] M. Ryuto, M. Ono, H. Izumi et al., "Induction of vascular endothelial growth factor by tumor necrosis factor $\alpha$ in human glioma cells: possible roles of SP-1," Journal of Biological Chemistry, vol. 271, no. 45, pp. 28220-28228, 1996.

[156] C. F. Deroanne, A. Hajitou, C.-M. Calberg-Bacq, B. V. Nusgens, and C. M. Lapière, "Angiogenesis by fibroblast growth factor 4 is mediated through an autocrine up-regulation of vascular endothelial growth factor expression," Cancer Research, vol. 57, no. 24, pp. 5590-5597, 1997.

[157] Q. T. Ho and C. J. Kuo, "Vascular endothelial growth factor: biology and therapeutic applications," International Journal of
Biochemistry and Cell Biology, vol. 39, no. 7-8, pp. 1349-1357, 2007.

[158] S. Frank, G. Hubner, G. Breier, M. T. Longaker, D. G. Greenhalgh, and S. Werner, "Regulation of vascular endothelial growth factor expression in cultured keratinocytes. Implications for normal and impaired wound healing," Journal of Biological Chemistry, vol. 270, no. 21, pp. 12607-12613, 1995.

[159] G. Finkenzeller, A. Sparacio, A. Technau, D. Marmé, and G. Siemeister, "Sp1 recognition sites in the proximal promoter of the human vascular endothelial growth factor gene are essential for platelet-derived growth factor-induced gene expression," Oncogene, vol. 15, no. 6, pp. 669-676, 1997.

[160] R. M. B. Loureiro and P. A. D’Amore, “Transcriptional regulation of vascular endothelial growth factor in cancer," Cytokine and Growth Factor Reviews, vol. 16, no. 1, pp. 77-89, 2005.

[161] S. Grugel, G. Finkenzeller, K. Weindel, B. Barleon, and D. Marme, "Both v-Ha-Ras and v-Raf stimulate expression of the vascular endothelial growth factor in NIH 3T3 cells," Journal of Biological Chemistry, vol. 270, no. 43, pp. 25915-25919, 1995.

[162] G. Siemeister, K. Weindel, K. Mohrs, B. Barleon, G. MartinyBaron, and D. Marmé, "Reversion of deregulated expression of vascular endothelial growth factor in human renal carcinoma cells by von Hippel-Lindau tumor suppressor protein," Cancer Research, vol. 56, no. 10, pp. 2299-2301, 1996.

[163] O. Iliopoulos, A. P. Levy, C. Jiang, W. G. Kaelin Jr., and M. A. Goldberg, "Negative regulation of hypoxia-inducible genes by the von Hippel-Lindau protein," Proceedings of the National Academy of Sciences of the United States of America, vol. 93, no. 20, pp. 10595-10599, 1996.

[164] K. Jin, M. Minami, J. Q. Lan et al., "Neurogenesis in dentate subgranular zone and rostral subventricular zone after focal cerebral ischemia in the rat," Proceedings of the National Academy of Sciences of the United States of America, vol. 98, no. 8, pp. 4710-4715, 2001.

[165] Y. Sun, K. Jin, J. T. Childs, L. Xie, X. O. Mao, and D. A. Greenberg, "Increased severity of cerebral ischemic injury in vascular endothelial growth factor-B-deficient mice," Journal of Cerebral Blood Flow and Metabolism, vol. 24, no. 10, pp. 1146$1152,2004$.

[166] Y. Sun, K. Jin, L. Xie et al., "VEGF-induced neuroprotection, neurogenesis, and angiogenesis after focal cerebral ischemia," Journal of Clinical Investigation, vol. 111, no. 12, pp. 1843-1851, 2003.

[167] F. Mackenzie and C. Ruhrberg, "Diverse roles for VEGF-A in the nervous system," Development, vol. 139, no. 8, pp. 1371-1380, 2012.

[168] J. M. Rosenstein, J. M. Krum, and C. Ruhrberg, "VEGF in the nervous system," Organogenesis, vol. 6, no. 2, pp. 107-114, 2010.

[169] D. N. Abrous, M. Koehl, and M. Le Moal, "Adult neurogenesis: from precursors to network and physiology," Physiological Reviews, vol. 85, no. 2, pp. 523-569, 2005.

[170] T. D. Palmer, A. R. Willhoite, and F. H. Gage, "Vascular niche for adult hippocampal neurogenesis," Journal of Comparative Neurology, vol. 425, no. 4, pp. 479-494, 2000.

[171] D. A. Greenberg and K. Jin, "From angiogenesis to neuropathology," Nature, vol. 438, no. 7070, pp. 954-959, 2005.

[172] P. Carmeliet and C. R. de Almodovar, "VEGF ligands and receptors: implications in neurodevelopment and neurodegeneration," Cellular and Molecular Life Sciences, vol. 70, no. 10, pp. 1763-1778, 2013. 
[173] A. Louissaint Jr., S. Rao, C. Leventhal, and S. A. Goldman, "Coordinated interaction of neurogenesis and angiogenesis in the adult songbird brain," Neuron, vol. 34, no. 6, pp. 945-960, 2002.

[174] K.-H. Jung, K. Chu, S.-T. Lee et al., "Granulocyte colonystimulating factor stimulates neurogenesis via vascular endothelial growth factor with STAT activation," Brain Research, vol. 1073-1074, no. 1, pp. 190-201, 2006.

[175] J. L. Warner-Schmidt and R. S. Duman, "VEGF as a potential target for therapeutic intervention in depression," Current Opinion in Pharmacology, vol. 8, no. 1, pp. 14-19, 2008.

[176] J. L. Warner-Schmidt and R. S. Duman, "Hippocampal neurogenesis: opposing effects of stress and antidepressant treatment," Hippocampus, vol. 16, no. 3, pp. 239-249, 2006.

[177] J. L. Warner-Schmidt and R. S. Duman, "VEGF is an essential mediator of the neurogenic and behavioral actions of antidepressants," Proceedings of the National Academy of Sciences of the United States of America, vol. 104, no. 11, pp. 4647-4652, 2007.

[178] L. Cao, X. Jiao, D. S. Zuzga et al., "VEGF links hippocampal activity with neurogenesis, learning and memory," Nature Genetics, vol. 36, no. 8, pp. 827-835, 2004.

[179] Y. Sun, K. Jin, J. T. Childs, L. Xie, X. O. Mao, and D. A. Greenberg, "Vascular endothelial growth factor-B (VEGFB) stimulates neurogenesis: evidence from knockout mice and growth factor administration," Developmental Biology, vol. 289, no. 2, pp. 329-335, 2006.

[180] C.-F. Calvo, R. H. Fontaine, J. Soueid et al., "Vascular endothelial growth factor receptor 3 directly regulates murine neurogenesis," Genes and Development, vol. 25, no. 8, pp. 831-844, 2011.

[181] D. A. Greenberg and K. Jin, "VEGF and ALS: the luckiest growth factor?" Trends in Molecular Medicine, vol. 10, no. 1, pp. 1-3, 2004.

[182] K. L. J. Kun Lin Jin, X. O. M. Xiao Ou Mao, and D. A. Greenberg, "Vascular endothelial growth factor rescues HN33 neural cells from death induced by serum withdrawal," Journal of Molecular Neuroscience, vol. 14, no. 3, pp. 197-203, 2000.

[183] H. Matsuzaki, M. Tamatani, A. Yamaguchi et al., "Vascular endothelial growth factor rescues hippocampal neurons from glutamate-induced toxicity: signal transduction cascades," The FASEB Journal, vol. 15, no. 7, pp. 1218-1220, 2001.

[184] K. Góra-Kupilas and J. Jośko, "The neuroprotective function of vascular endothelial growth factor (VEGF)," Folia Neuropathologica, vol. 43, no. 1, pp. 31-39, 2005.

[185] M. Volm, J. Mattern, and R. Koomägi, "Inverse correlation between apoptotic (Fas ligand, caspase-3) and angiogenic factors (VEGF, microvessel density) in squamous cell lung carcinomas," Anticancer Research, vol. 19, no. 3A, pp. 1669-1671, 1999.

[186] G. Cao, Y. Luo, T. Nagayama et al., "Cloning and characterization ot rat caspase-9: implications for a role in mediating caspase-3 activation and hippocampal cell death after transient cerebral ischemia," Journal of Cerebral Blood Flow and Metabolism, vol. 22, no. 5, pp. 534-546, 2002.

[187] S. H. Graham and J. Chen, "Programmed cell death in cerebral ischemia," Journal of Cerebral Blood Flow and Metabolism, vol. 21, no. 2, pp. 99-109, 2001.

[188] R. Motterlini, R. Foresti, R. Bassi, V. Calabrese, J. E. Clark, and C. J. Green, "Endothelial heme oxygenase-1 induction by hypoxia. Modulation by inducible nitric-oxide synthase and Snitrosothiols," Journal of Biological Chemistry, vol. 275, no. 18, pp. 13613-13620, 2000.
[189] A. Nishie, M. Ono, T. Shono et al., "Macrophage infiltration and heme oxygenase- 1 expression correlate with angiogenesis in human gliomas," Clinical Cancer Research, vol. 5, no. 5, pp. 1107-1113, 1999.

[190] S. W. Ryter, M. Si, C.-C. Lai, and C.-Y. Su, "Regulation of endothelial heme oxygenase activity during hypoxia is dependent on chelatable iron," American Journal of Physiology-Heart and Circulatory Physiology, vol. 279, no. 6, pp. H2889-H2897, 2000.

[191] D. Dantz, J. Bewersdorf, B. Fruehwald-Schultes et al., "Vascular endothelial growth factor: a novel endocrine defensive response to hypoglycemia," Journal of Clinical Endocrinology and Metabolism, vol. 87, no. 2, pp. 835-840, 2002.

[192] S. E. Bearden and S. S. Segal, "Microvessels promote motor nerve survival and regeneration through local VEGF release following ectopic reattachment," Microcirculation, vol. 11, no. 8, pp. 633-644, 2004.

[193] D. Foehring, B. Brand-Saberi, and C. Theiss, "VEGF-induced growth cone enhancement is diminished by inhibiting tyrosineresidue 1214 of VEGFR-2," Cells Tissues Organs, vol. 196, pp. 195205, 2012.

[194] F. Forstreuter, R. Lucius, and R. Mentlein, "Vascular endothelial growth factor induces chemotaxis and proliferation of microglial cells," Journal of Neuroimmunology, vol. 132, no. 1-2, pp. 93-98, 2002.

[195] E. Herrán, R. Pérez-González, M. Igartua, J. Pedraz, E. Carro, and R. Hernández, "VEGF-releasing biodegradable nanospheres administered by craniotomy: a novel therapeutic approach in the APP/Ps1 mouse model of Alzheimer's disease," Journal of Controlled Release, vol. 170, no. 1, pp. 111-119, 2013.

[196] N. Mani, A. Khaibullina, J. M. Krum, and J. M. Rosenstein, "Astrocyte growth effects of vascular endothelial growth factor (VEGF) application to perinatal neocortical explants: receptor mediation and signal transduction pathways," Experimental Neurology, vol. 192, no. 2, pp. 394-406, 2005.

[197] J. H. P. Skene and D. W. Cleveland, "Hypoxia and lou gehrig," Nature Genetics, vol. 28, no. 2, pp. 107-108, 2001.

[198] O. P. Keifer Jr., D. M. O’Connor, and N. M. Boulis, "Gene and protein therapies utilizing VEGF for ALS," Pharmacology \& Therapeutics, vol. 141, no. 3, pp. 261-271, 2014.

[199] B. J. Turner and K. Talbot, "Transgenics, toxicity and therapeutics in rodent models of mutant SOD1-mediated familial ALS," Progress in Neurobiology, vol. 85, no. 1, pp. 94-134, 2008.

[200] L. Lu, L. Zheng, L. Viera et al., "Mutant Cu/Zn-superoxide dismutase associated with amyotrophic lateral sclerosis destabilizes vascular endothelial growth factor mRNA and downregulates its expression," Journal of Neuroscience, vol. 27, no. 30, pp. 7929-7938, 2007.

[201] X. Li, C. Lee, Z. Tang et al., "VEGF-B: a survival, or an angiogenic factor?" Cell Adhesion and Migration, vol. 3, no. 4, pp. 322-327, 2009.

[202] L. Lu, S. Wang, L. Zheng et al., "Amyotrophic lateral sclerosislinked mutant SOD1 sequesters $\mathrm{Hu}$ antigen $\mathrm{R}(\mathrm{HuR})$ and TIA-1-related protein (TIAR). Implications for impaired posttranscriptional regulation of vascular endothelial growth factor," Journal of Biological Chemistry, vol. 284, no. 49, pp. 3398933998, 2009.

[203] L. Van Den Bosch, E. Storkebaum, V. Vleminckx et al., "Effects of vascular endothelial growth factor (VEGF) on motor neuron degeneration," Neurobiology of Disease, vol. 17, no. 1, pp. 21-28, 2004 . 
[204] T. Murakami, H. Ilieva, M. Shiote et al., "Hypoxic induction of vascular endothelial growth factor is selectively impaired in mice carrying the mutant SOD1 gene," Brain Research, vol. 989, no. 2, pp. 231-237, 2003.

[205] J. Lladó, L. Tolosa, and G. Olmos, "Cellular and molecular mechanisms involved in the neuroprotective effects of VEGF on motoneurons," Frontiers in Cellular Neuroscience, vol. 7, article 181, 2013.

[206] Z. Zhong, R. Deane, Z. Ali et al., "ALS-causing SOD1 mutants generate vascular changes prior to motor neuron degeneration," Nature Neuroscience, vol. 11, no. 4, pp. 420-422, 2008.

[207] L. Tolosa, M. Mir, V. J. Asensio, G. Olmos, and J. Lladó, "Vascular endothelial growth factor protects spinal cord motoneurons against glutamate-induced excitotoxicity via phosphatidylinositol 3-kinase," Journal of Neurochemistry, vol. 105, no. 4, pp. 10801090, 2008.

[208] L. B. Tovar-y-Romo and R. Tapia, "VEGF protects spinal motor neurons against chronic excitotoxic degeneration in vivo by activation of PI3-K pathway and inhibition of p38MAPK," Journal of Neurochemistry, vol. 115, no. 5, pp. 1090-1101, 2010.

[209] O. O. Ogunshola, A. Antic, M. J. Donoghue et al., "Paracrine and autocrine functions of neuronal vascular endothelial growth factor (VEGF) in the central nervous system," Journal of Biological Chemistry, vol. 277, no. 13, pp. 11410-11415, 2002.

[210] A. Brockington, S. B. Wharton, M. Fernando et al., "Expression of vascular endothelial growth factor and its receptors in the central nervous system in amyotrophic lateral sclerosis," Journal of Neuropathology and Experimental Neurology, vol. 65, no. 1, pp. 26-36, 2006.

[211] E. Storkebaum, D. Lambrechts, M. Dewerchin et al., "Treatment of motoneuron degeneration by intracerebroventricular delivery of VEGF in a rat model of ALS," Nature Neuroscience, vol. 8, no. 1, pp. 85-92, 2005.

[212] N. Beazley-Long, J. Hua, T. Jehle et al., "VEGF- $A_{165} b$ is an endogenous neuroprotective splice isoform of vascular endothelial growth factor A in Vivo and in Vitro," The American Journal of Pathology, vol. 183, no. 3, pp. 918-929, 2013.

[213] R. Lemmens, A. Van Hoecke, N. Hersmus et al., "Overexpression of mutant superoxide dismutase 1 causes a motor axonopathy in the zebrafish," Human Molecular Genetics, vol. 16, no. 19, pp. 2359-2365, 2007.

[214] M. M. Da Costa, C. E. Allen, A. Higginbottom, T. Ramesh, P. J. Shaw, and C. J. McDermott, "A new zebrafish model produced by TILLING of SOD1-related amyotrophic lateral sclerosis replicates key features of the disease and represents a tool for in vivo therapeutic screening," Disease Models \& Mechanisms, vol. 7, no. 1, pp. 73-81, 2014.

[215] B. Li, W. Xu, C. Luo, D. Gozal, and R. Liu, "VEGF-induced activation of the PI3-K/Akt pathway reduces mutant SOD1mediated motor neuron cell death," Molecular Brain Research, vol. 111, no. 1-2, pp. 155-164, 2003.

[216] X. Li, "VEGF-B: a thing of beauty," Cell Research, vol. 20, no. 7, pp. 741-744, 2010.

[217] Y. Li, F. Zhang, N. Nagai et al., "VEGF-B inhibits apoptosis via VEGFR-1-mediated suppression of the expression of BH3-only protein genes in mice and rats," Journal of Clinical Investigation, vol. 118, no. 3, pp. 913-923, 2008.

[218] F. Zhang, Z. Tang, X. Hou et al., "VEGF-B is dispensable for blood vessel growth but critical for their survival, and VEGF-B targeting inhibits pathological angiogenesis," Proceedings of the National Academy of Sciences of the United States of America, vol. 106, no. 15, pp. 6152-6157, 2009.
[219] X. Li, A. Kumar, F. Zhang, C. Lee, and Z. Tang, "Complicated life, complicated VEGF-B," Trends in Molecular Medicine, vol. 18, no. 2, pp. 119-127, 2012.

[220] K. Poesen, D. Lambrechts, P. Van Damme et al., "Novel role for vascular endothelial growth factor (VEGF) receptor-1 and its ligand VEGF-B in motor neuron degeneration," Journal of Neuroscience, vol. 28, no. 42, pp. 10451-10459, 2008.

[221] M. R. Harrigan, S. R. Ennis, S. E. Sullivan, and R. F. Keep, "Effects of intraventricular infusion of vascular endothelial growth factor on cerebral blood flow, edema, and infarct volume," Acta Neurochirurgica, vol. 145, no. 1, pp. 49-53, 2003.

[222] L. Xie, X. Mao, K. Jin, and D. A. Greenberg, "Vascular endothelial growth factor-B expression in postischemic rat brain," Vascular Cell, vol. 5, no. 1, pp. 1-5, 2013.

[223] M. Koppers, M. van Es, L. H. van den Berg, J. H. Veldink, and R. J. Pasterkamp, "Genetics of amyotrophic lateral sclerosis," in Amyotrophic Lateral Sclerosis, pp. 479-516, InTech, New York, NY, USA, 2012.

[224] A. Brockington, J. Kirby, D. Eggitt et al., "Screening of the regulatory and coding regions of vascular endothelial growth factor in amyotrophic lateral sclerosis," Neurogenetics, vol. 6, no. 2, pp. 101-104, 2005.

[225] F. Gros-Louis, S. Laurent, A. A. S. Lopes et al., "Absence of mutations in the hypoxia response element of VEGF in ALS," Muscle and Nerve, vol. 28, no. 6, pp. 774-775, 2003.

[226] D. Lambrechts, K. Poesen, R. Fernández-Santiago et al., "Metaanalysis of vascular endothelial growth factor variations in amyotrophic lateral sclerosis: increased susceptibility in male carriers of the -2578AA genotype," Journal of Medical Genetics, vol. 46, no. 12, pp. 840-846, 2009.

[227] P. D. Terry, F. Kamel, D. M. Umbach et al., "VEGF promoter haplotype and amyotrophic lateral sclerosis (ALS)," Journal of Neurogenetics, vol. 18, no. 2, pp. 429-434, 2004.

[228] G. N. Avakian, A. A. Nikonov, E. A. Katunina, V. N. Avakian, A. A. Nikonova, and E. I. Gusev, "Differential diagnostic criteria of lateral amyotrophic sclerosis," Zhurnal Nevrologii i Psikhiatrii Imeni S.S. Korsakova / Ministerstvo Zdravookhraneniia $i$ Meditsinskoi Promyshlennosti Rossiiskoi Federatsii, Vserossiiskoe Obshchestvo Nevrologov [i] Vserossiiskoe Obshchestvo Psikhiatrov, vol. 102, no. 1, pp. 22-25, 2002.

[229] Y. Zhang, H. Zhang, Y. Fu et al., "VEGF C2578A polymorphism does not contribute to amyotrophic lateral sclerosis susceptibility in sporadic Chinese patients," Amyotrophic Lateral Sclerosis, vol. 7, no. 2, pp. 119-122, 2006.

[230] R. Del Bo, M. Scarlato, S. Ghezzi et al., "Absence of angiogenic genes modification in Italian ALS patients," Neurobiology of Aging, vol. 29, no. 2, pp. 314-316, 2008.

[231] P. W. J. Van Vught, N. A. Sutedja, J. H. Veldink et al., "Lack of association between VEGF polymorphisms and ALS in a Dutch population," Neurology, vol. 65, no. 10, pp. 1643-1645, 2005.

[232] R. Fernández-Santiago, M. Sharma, J. C. Mueller et al., "Possible gender-dependent association of vascular endothelial growth factor (VEGF) gene and ALS," Neurology, vol. 66, no. 12, pp. 1929-1931, 2006.

[233] W. Chen, M. Saeed, H. Mao et al., "Lack of association of VEGF promoter polymorphisms with sporadic ALS," Neurology, vol. 67, no. 3, pp. 508-510, 2006.

[234] E. Hormbrey, P. Gillespie, K. Turner et al., "A critical review of vascular endothelial growth factor (VEGF) analysis in peripheral blood: is the current literature meaningful?" Clinical and Experimental Metastasis, vol. 19, no. 8, pp. 651-663, 2002. 
[235] E. Nobile-Orazio, F. Terenghi, C. Giannotta, F. Gallia, and A. Nozza, "Serum vegf levels in poems syndrome and in immunemediated neuropathies," Neurology, vol. 72, no. 11, pp. 10241026, 2009.

[236] I. Nygren, A. Larsson, A. Johansson, and H. Askmark, "VEGF is increased in serum but not in spinal cord from patients with amyotrophic lateral sclerosis," NeuroReport, vol. 13, no. 17, pp. 2199-2201, 2002.

[237] N. Just, C. Moreau, P. Lassalle et al., "High erythropoietin and low vascular endothelial growth factor levels in cerebrospinal fluid from hypoxemic ALS patients suggest an abnormal response to hypoxia," Neuromuscular Disorders, vol. 17, no. 2, pp. 169-173, 2007.

[238] D. Devos, C. Moreau, P. Lassalle et al., "Low levels of the vascular endothelial growth factor in CSF from early ALS patients," Neurology, vol. 62, no. 11, pp. 2127-2129, 2004.

[239] C. Moreau, D. Devos, V. Brunaud-Danel et al., "Paradoxical response of VEGF expression to hypoxia in CSF of patients with ALS," Journal of Neurology, Neurosurgery and Psychiatry, vol. 77, no. 2, pp. 255-257, 2006.

[240] R. Carilho, M. de Carvalho, M. Swash, S. Pinto, A. Pinto, and J. Costa, "Vascular endothelial growth factor and amyotrophic lateral sclerosis: the Interplay with exercise and non-invasive ventilation," Muscle \& Nerve, vol. 49, pp. 545-550, 2013.

[241] C. Moreau, P. Gosset, J. Kluza et al., "Deregulation of the hypoxia inducible factor- $1 \alpha$ pathway in monocytes from sporadic amyotrophic lateral sclerosis patients," Neuroscience, vol. 172, pp. 110-117, 2011.

[242] P. K. Gupta, S. Prabhakar, S. Sharma, and A. Anand, "Vascular endothelial growth factor-A (VEGF-A) and chemokine ligand-2 (CCL2) in amyotrophic lateral sclerosis (ALS) patients," Journal of Neuroinflammation, vol. 8, article 97, 2011.

[243] J. Ilzecka, "Cerebrospinal fluid vascular endothelial growth factor in patients with amyotrophic lateral sclerosis," Clinical Neurology and Neurosurgery, vol. 106, no. 4, pp. 289-293, 2004.

[244] C. Moreau, P. Gosset, V. Brunaud-Danel et al., "CSF profiles of angiogenic and inflammatory factors depend on the respiratory status of ALS patients," Amyotrophic Lateral Sclerosis, vol. 10, no. 3, pp. 175-181, 2009.

[245] E. C. Breen, E. C. Johnson, H. Wagner, H.-M. Tseng, L. A. Sung, and P. D. Wagner, "Angiogenic growth factor mRNA responses in muscle to a single bout of exercise," Journal of Applied Physiology, vol. 81, no. 1, pp. 355-361, 1996.

[246] S. Sathasivam, "VEGF and ALS," Neuroscience Research, vol. 62, no. 2, pp. 71-77, 2008.

[247] M. Azimi-Nezhad, D. Lambert, C. Ottone et al., "Influence of pre-analytical variables on VEGF gene expression and circulating protein concentrations," Biopreservation and Biobanking, vol. 10, no. 5, pp. 454-461, 2012.

[248] M. L. Hetland, I. J. Christensen, T. Lottenburger et al., "Circulating VEGF as a biological marker in patients with rheumatoid arthritis? Preanalytical and biological variability in healthy persons and in patients," Disease Markers, vol. 24, no. 1, pp. 1-10, 2008.

[249] A. Brockington, B. Wokke, H. Nixon, J. A. Hartley, and P. J. Shaw, "Screening of the transcriptional regulatory regions of vascular endothelial growth factor receptor 2 (VEGFR2) in amyotrophic lateral sclerosis," BMC Medical Genetics, vol. 8, article 23, 2007.

[250] M. Dewil, D. Lambrechts, R. Sciot et al., "Vascular endothelial growth factor counteracts the loss of phospho-Akt preceding motor neurone degeneration in amyotrophic lateral sclerosis," Neuropathology and Applied Neurobiology, vol. 33, no. 5, pp. 499-509, 2007.

[251] E. Bogaert, P. Van Damme, K. Poesen et al., "VEGF protects motor neurons against excitotoxicity by upregulation of GluR2," Neurobiology of Aging, vol. 31, no. 12, pp. 2185-2191, 2010.

[252] P. Van Damme, E. Bogaert, M. Dewil et al., "Astrocytes regulate GluR2 expression in motor neurons and their vulnerability to excitotoxicity," Proceedings of the National Academy of Sciences of the United States of America, vol. 104, no. 37, pp. 14825-14830, 2007.

[253] P. Van Damme, L. Van Den Bosch, E. Van Houtte, G. Callewaert, and W. Robberecht, "GluR2-dependent properties of AMPA receptors determine the selective vulnerability of motor neurons to excitotoxicity," Journal of Neurophysiology, vol. 88, no. 3, pp. 1279-1287, 2002.

[254] C. Zheng, I. Nennesmo, B. Fadeel, and J.-I. Henter, "Vascular endothelial growth factor prolongs survival in a transgenic mouse model of ALS," Annals of Neurology, vol. 56, no. 4, pp. 564-567, 2004.

[255] J.-P. Yang, H.-J. Liu, S.-M. Cheng et al., "Direct transport of VEGF from the nasal cavity to brain," Neuroscience Letters, vol. 449, no. 2, pp. 108-111, 2009.

[256] J. C. Dodge, C. M. Treleaven, J. A. Fidler et al., "AAV4-mediated expression of IGF-1 and VEGF within cellular components of the ventricular system improves survival outcome in familial ALS mice," Molecular Therapy, vol. 18, no. 12, pp. 2075-2084, 2010.

[257] S. A. Sakowski, S. B. Heavener, J. S. Lunn et al., "Neuroprotection using gene therapy to induce vascular endothelial growth factor-A expression," Gene Therapy, vol. 16, no. 11, pp. 1292-1299, 2009.

[258] M. A. Kliem, B. L. Heeke, C. K. Franz et al., "Intramuscular administration of a VEGF zinc finger transcription factor activator (VEGF-ZFP-TF) improves functional outcomes in SOD1 rats," Amyotrophic Lateral Sclerosis, vol. 12, no. 5, pp. 331339, 2011.

[259] M. Shiote, I. Nagano, H. Ilieva et al., "Reduction of a vascular endothelial growth factor receptor, fetal liver kinase-1, by antisense oligonucleotides induces motor neuron death in rat spinal cord exposed to hypoxia," Neuroscience, vol. 132, no. 1, pp. 175-182, 2005.

[260] Y. D. Teng, S. C. Benn, S. N. Kalkanis et al., "Multimodal actions of neural stem cells in a mouse model of ALS: a metaanalysis," Science Translational Medicine, vol. 4, no. 165, Article ID 165ra164, 2012.

[261] L. Ferraiuolo, A. Frakes, and B. K. Kaspar, "Neural stem cells as a therapeutic approach for amyotrophic lateral sclerosis," Molecular Therapy, vol. 21, no. 3, pp. 503-505, 2013.

[262] D. H. Hwang, H. J. Lee, I. H. Park et al., "Intrathecal transplantation of human neural stem cells overexpressing VEGF provide behavioral improvement, disease onset delay and survival extension in transgenic ALS mice," Gene Therapy, vol. 16, no. 10, pp. 1234-1244, 2009.

[263] C. Zhang, C. Zhou, J.-J. Teng, R.-L. Zhao, and Y.-Q. Song, "Multiple administrations of human marrow stromal cells through cerebrospinal fluid prolong survival in a transgenic mouse model of amyotrophic lateral sclerosis," Cytotherapy, vol. 11, no. 3, pp. 299-306, 2009.

[264] D. Krakora, P. Mulcrone, M. Meyer et al., "Synergistic effects of GDNF and VEGF on lifespan and disease progression in a 
familial ALS rat model," Molecular Therapy, vol. 21, no. 8, pp. 1602-1610, 2013.

[265] R. Gu, X. Hou, R. Pang et al., "Human adipose-derived stem cells enhance the glutamate uptake function of GLT1 in SOD1G93A-bearing astrocytes," Biochemical and Biophysical Research Communications, vol. 393, no. 3, pp. 481-486, 2010.

[266] G. Constantin, S. Marconi, B. Rossi et al., "Adipose-derived mesenchymal stem cells ameliorate chronic experimental autoimmune encephalomyelitis," Stem Cells, vol. 27, no. 10, pp. 26242635, 2009.

[267] S. Marconi, G. Castiglione, E. Turano et al., "Human adiposederived mesenchymal stem cells systemically injected promote peripheral nerve regeneration in the mouse model of sciatic crush," Tissue Engineering Part A, vol. 18, no. 11-12, pp. 12641272, 2012.

[268] S. Marconi, M. Bonaconsa, I. Scambi et al., "Systemic treatment with adipose-derived mesenchymal stem cells ameliorates clinical and pathological features in the amyotrophic lateral sclerosis murine model," Neuroscience, vol. 248C, pp. 333-343, 2013.

[269] S. Corti, M. Nizzardo, M. Nardini et al., "Systemic transplantation of c-kit+ cells exerts a therapeutic effect in a model of amyotrophic lateral sclerosis," Human Molecular Genetics, vol. 19, no. 19, pp. 3782-3796, 2010.

[270] R. S. Pandya, L. L. J. Mao, E. W. Zhou et al., "Neuroprotection for amyotrophic lateral sclerosis: role of stem cells, growth factors, and gene therapy," Central Nervous System Agents in Medicinal Chemistry, vol. 12, no. 1, pp. 15-27, 2012.

[271] A. A. Rizvanov, A. P. Kiyasov, I. M. Gaziziov et al., "Human umbilical cord blood cells transfected with VEGF and L1CAM do not differentiate into neurons but transform into vascular endothelial cells and secrete neuro-trophic factors to support neuro-genesis-a novel approach in stem cell therapy," Neurochemistry International, vol. 53, no. 6-8, pp. 389-394, 2008.

[272] M. A. Proescholdt, J. D. Heiss, S. Walbridge et al., "Vascular endothelial growth factor (VEGF) modulates vascular permeability and inflammation in rat brain," Journal of Neuropathology and Experimental Neurology, vol. 58, no. 6, pp. 613-627, 1999.

[273] D. H. Dobrogowska, A. S. Lossinsky, M. Tarnawski, and A. W. Vorbrodt, "Increased blood-brain barrier permeability and endothelial abnormalities induced by vascular endothelial growth factor," Journal of Neurocytology, vol. 27, no. 3, pp. 163$173,1998$.

[274] M. De Carvalho, M. Scotto, A. Lopes, and M. Swash, "Quantitating progression in ALS," Neurology, vol. 64, no. 10, pp. 17831785, 2005.

[275] A. H. Ropper, K. C. Gorson, C. L. Gooch et al., "Vascular endothelial growth factor gene transfer for diabetic polyneuropathy: a randomized, double-blinded trial," Annals of Neurology, vol. 65, no. 4, pp. 386-393, 2009.

[276] Z.-G. Wang, T. S. Puri, and R. J. Quigg, "Characterization of novel VEGF (vascular endothelial growth factor)-C splicing isoforms from mouse," Biochemical Journal, vol. 428, no. 3, pp. 347-354, 2010.

[277] A. Schänzer, F.-P. Wachs, D. Wilhelm et al., "Direct stimulation of adult neural stem cells in vitro and neurogenesis in vivo by vascular endothelial growth factor," Brain Pathology, vol. 14, no. 3, pp. 237-248, 2004.

[278] T. Hashimoto, X.-M. Zhang, B. Y.-K. Chen, and X.-J. Yang, "VEGF activates divergent intracellular signaling components to regulate retinal progenitor cell proliferation and neuronal differentiation," Development, vol. 133, no. 11, pp. 2201-2210, 2006.

[279] C. M. Schwartz, T. Tavakoli, C. Jamias et al., "Stromal factors SDF1 $\alpha$, sFRP1, and VEGFD induce dopaminergic neuron differentiation of human pluripotent stem cells," Journal of Neuroscience Research, vol. 90, no. 7, pp. 1367-1381, 2012.

[280] L. Erskine, S. Reijntjes, T. Pratt et al., "VEGF signaling through neuropilin 1 guides commissural axon crossing at the optic chiasm," Neuron, vol. 70, no. 5, pp. 951-965, 2011.

[281] C. Ruiz de Almodovar, P. J. Fabre, E. Knevels et al., "VEGF mediates commissural axon chemoattraction through its receptor Flk1," Neuron, vol. 70, no. 5, pp. 966-978, 2011.

[282] J. M. Rosenstein, N. Mani, A. Khaibullina, and J. M. Krum, "Neurotrophic effects of vascular endothelial growth factor on organotypic cortical explants and primary cortical neurons," Journal of Neuroscience, vol. 23, no. 35, pp. 11036-11044, 2003.

[283] B. Svensson, M. Peters, H.-G. König et al., "Vascular endothelial growth factor protects cultured rat hippocampal neurons against hypoxic injury via an antiexcitotoxic, caspaseindependent mechanism," Journal of Cerebral Blood Flow and Metabolism, vol. 22, no. 10, pp. 1170-1175, 2002.

[284] Y. Ma, W. Liu, Y. Wang et al., "VEGF protects rat cortical neurons from mechanical trauma injury induced apoptosis via the MEK/ERK pathway," Brain Research Bulletin, vol. 86, no. 56, pp. 441-446, 2011.

[285] Y.-J. Shin, J.-S. Choi, J.-Y. Lee et al., "Differential regulation of vascular endothelial growth factor- $\mathrm{C}$ and its receptor in the rat hippocampus following transient forebrain ischemia," Acta Neuropathologica, vol. 116, no. 5, pp. 517-527, 2008.

[286] S. Kranich, K. Hattermann, A. Specht, R. Lucius, and R. Mentlein, "VEGFR-3/Flt-4 mediates proliferation and chemotaxis in glial precursor cells," Neurochemistry International, vol. 55, no. 8, pp. 747-753, 2009.

[287] D. Mauceri, H. E. Freitag, A. M. M. Oliveira, C. P. Bengtson, and H. Bading, "Nuclear calcium-VEGFD signaling controls maintenance of dendrite arborization necessary for memory formation," Neuron, vol. 71, no. 1, pp. 117-130, 2011.

[288] H. Beck, T. Acker, A. W. Püschel, H. Fujisawa, P. Carmeliet, and K. H. Plate, "Cell type-specific expression of neuropilins in an MCA-occlusion model in mice suggests a potential role in post-ischemic brain remodeling," Journal of Neuropathology and Experimental Neurology, vol. 61, no. 4, pp. 339-350, 2002.

[289] H. Du, P. Li, Y. Pan et al., "Vascular endothelial growth factor signaling implicated in neuroprotective effects of placental growth factor in an in vitro ischemic model," Brain Research, vol. 1357, pp. 1-8, 2010.

[290] B. W. Kim, M. Choi, Y.-S. Kim et al., "Vascular endothelial growth factor (VEGF) signaling regulates hippocampal neurons by elevation of intracellular calcium and activation of calcium/calmodulin protein kinase II and mammalian target of rapamycin," Cellular Signalling, vol. 20, no. 4, pp. 714-725, 2008.

[291] T. Licht, R. Eavri, I. Goshen, Y. Shlomai, A. Mizrahi, and E. Keshet, "VEGF is required for dendritogenesis of newly born olfactory bulb interneurons," Development, vol. 137, no. 2, pp. 261-271, 2010.

[292] T. Licht, I. Goshen, A. Avital et al., "Reversible modulations of neuronal plasticity by VEGF," Proceedings of the National Academy of Sciences of the United States of America, vol. 108, no. 12, pp. 5081-5086, 2011.

[293] T. Licht and E. Keshet, "Delineating multiple functions of VEGF-A in the adult brain," Cellular and Molecular Life Sciences, vol. 70, no. 10, pp. 1727-1737, 2013. 
[294] P. Proia, G. Schiera, M. Mineo et al., "Astrocytes shed extracellular vesicles that contain fibroblast growth factor- 2 and vascular endothelial growth factor," International Journal of Molecular Medicine, vol. 21, no. 1, pp. 63-67, 2008.

[295] G. Schiera, P. Proia, C. Alberti, M. Mineo, G. Savettieri, and I. Di Liegro, "Neurons produce FGF2 and VEGF and secrete them at least in part by shedding extracellular vesicles," Journal of Cellular and Molecular Medicine, vol. 11, no. 6, pp. 1384-1394, 2007.

[296] M. Sondell, F. Sundler, and M. Kanje, "Vascular endothelial growth factor is a neurotrophic factor which stimulates axonal outgrowth through the flk-1 receptor," European Journal of Neuroscience, vol. 12, no. 12, pp. 4243-4254, 2000.

[297] A. Bellon, J. Luchino, K. Haigh et al., "VEGFR2 (KDR/Flk1) signaling mediates axon growth in response to semaphorin $3 \mathrm{E}$ in the developing brain," Neuron, vol. 66, no. 2, pp. 205-219, 2010.

[298] M. R. Pitzer, C. E. Sortwell, B. F. Daley et al., "Angiogenic and neurotrophic effects of vascular endothelial growth factor (VEGF165): studies of grafted and cultured embryonic ventral mesencephalic cells," Experimental Neurology, vol. 182, no. 2, pp. 435-445, 2003. 

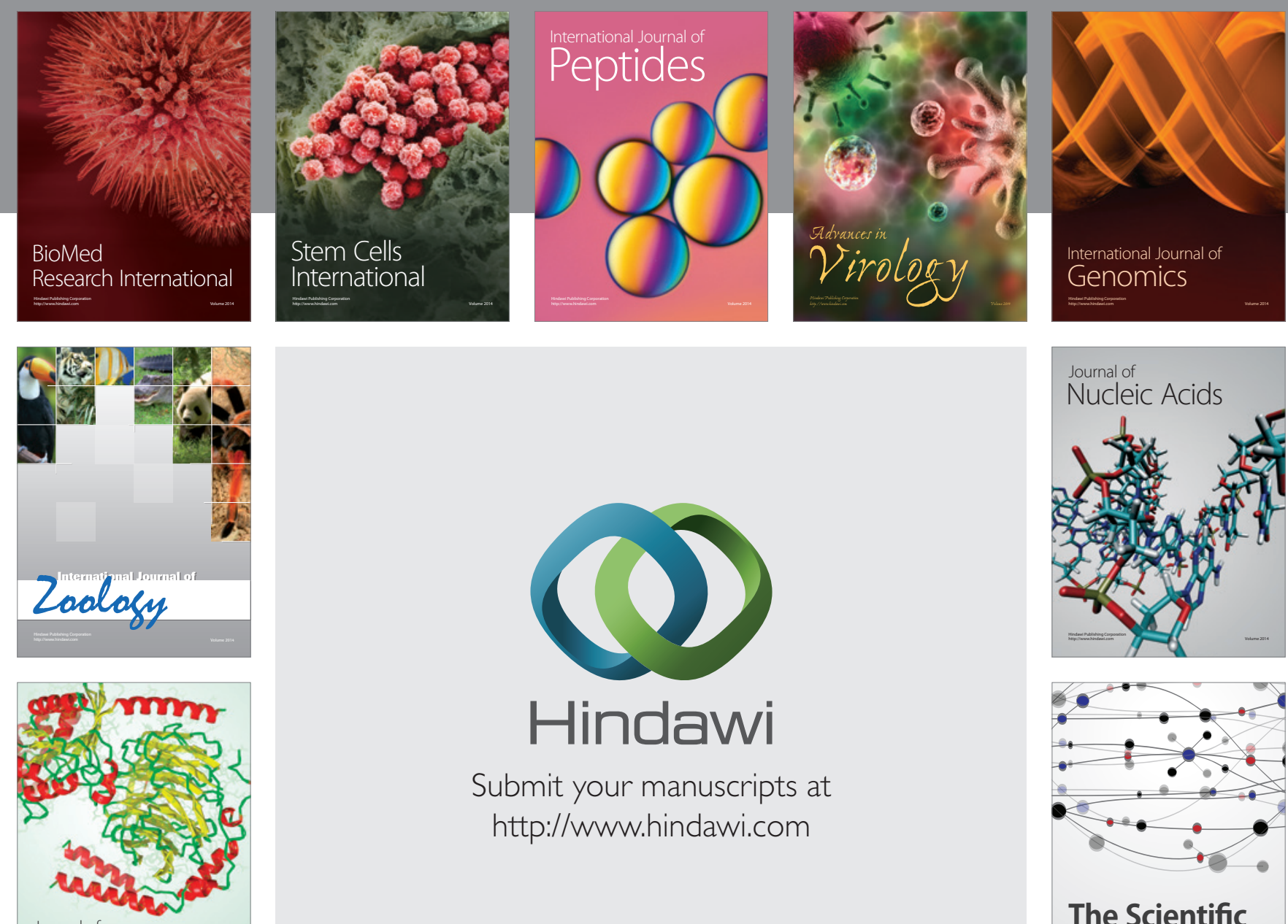

Submit your manuscripts at

http://www.hindawi.com

Journal of
Signal Transduction
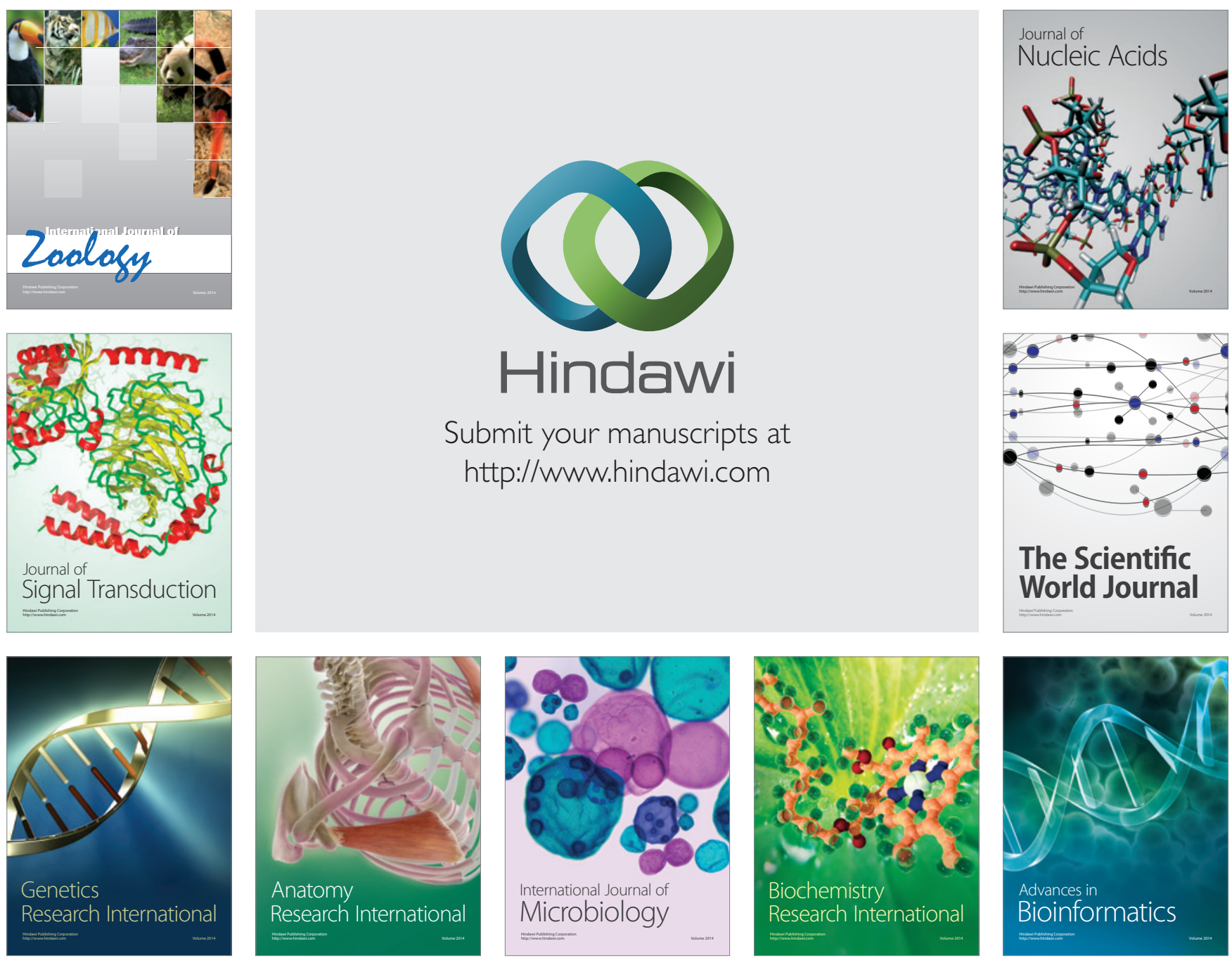

The Scientific World Journal
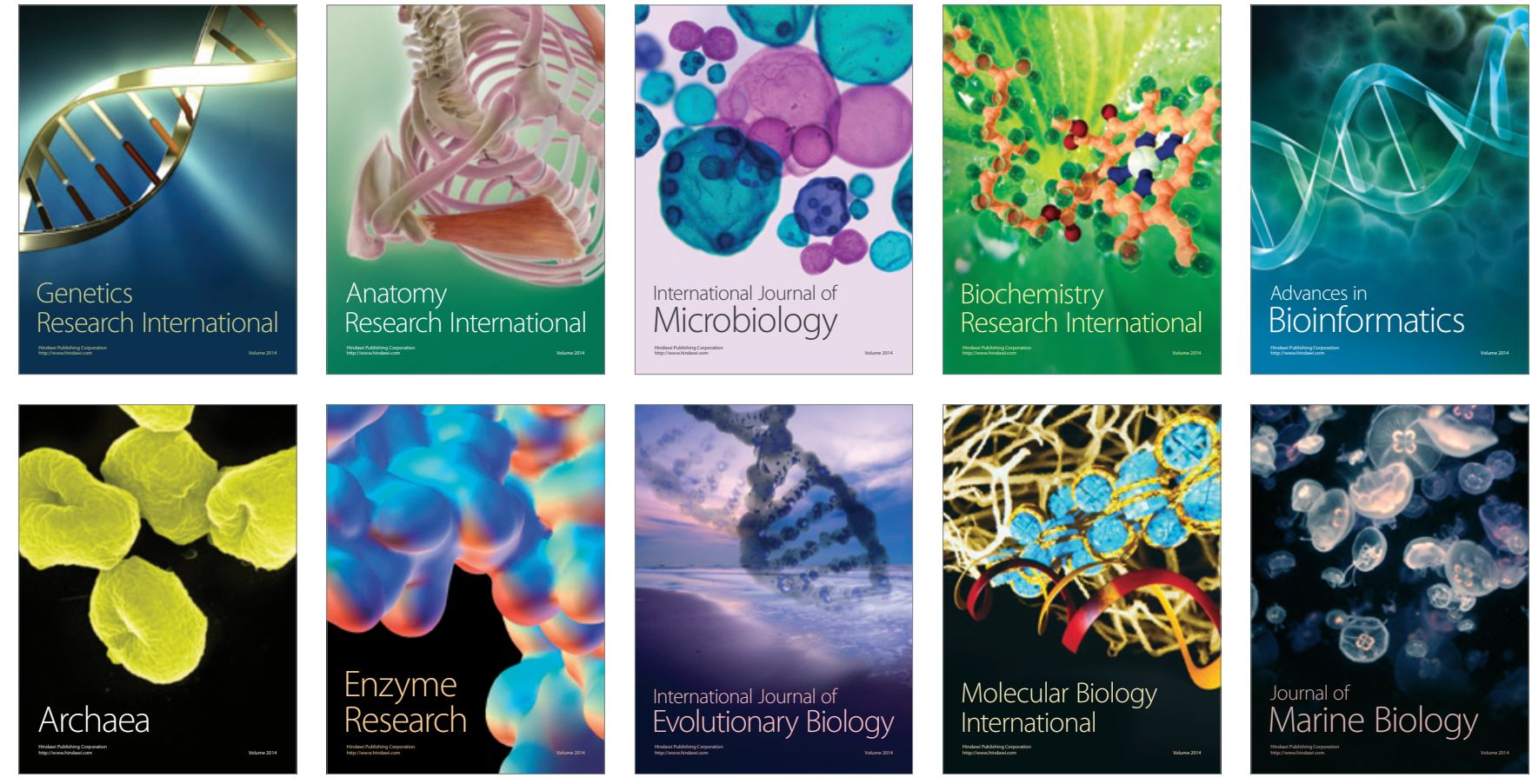